\title{
Monomer- and polymer radicals of vinyl compounds: EPR and DFT studies of geometric and electronic structures in the adsorbed state
}

Anders Lund and Marek Danilczuk

\section{Linköping University Post Print}

N.B.: When citing this work, cite the original article.

Original Publication:

Anders Lund and Marek Danilczuk, Monomer- and polymer radicals of vinyl compounds: EPR and DFT studies of geometric and electronic structures in the adsorbed state, 2012, Spectrochimica Acta Part A - Molecular and Biomolecular Spectroscopy, (98), 367-377.

http://dx.doi.org/10.1016/j.saa.2012.08.054

Copyright: Elsevier http://www.elsevier.com/

Postprint available at: Linköping University Electronic Press http://urn.kb.se/resolve?urn=urn:nbn:se:liu:diva-86112 
Monomer- and Polymer radicals of Vinyl Compounds: EPR and DFT Studies of Geometric and Electronic Structures in the Adsorbed State

Anders Lund ${ }^{\mathrm{a}^{*}}$ and Marek Danilczuk ${ }^{\mathrm{b}}$

${ }^{a}$ Department of Physics, Chemistry and Biology, IFM, Linköping University, S-581 83

Linköping, Sweden

${ }^{b}$ Institute of Nuclear Chemistry and Technology, Dorodna 16, 03-195 Warsaw, Poland

Corresponding author:

Anders Lund

e-mail: alund@ifm.liu.se 


\begin{abstract}
Electron paramagnetic resonance (EPR) spectroscopy was applied to study the paramagnetic species formed from styrene, 1,1-diphenylethylene, $\alpha$-methylstyrene, $\beta$-methylstyrene and methylmethacrylate adsorbed on amorphous silica gel after $\gamma$-irradiation at $77 \mathrm{~K}$. Radicals formed by the hydrogen atom addition at the vinyl group of the monomers were observed in all samples. The hydrogen atoms were shown to originate to a large extent from the adsorbent by using silica gel with deuterated silanol groups. An EPR spectrum assigned to a propagating radical was observed at increased temperature for samples containing methylmethacrylate (MMA). The structures of the adsorption complexes, the respective hyperfine coupling constants and the adsorption energies were calculated by applying DFT quantum chemical methods. The reaction between an MMA molecule and the MMA radical and the structure of the propagating radical was modeled. The calculated hyperfine coupling constants for all radicals confirmed the assignment of the experimental spectra.
\end{abstract}




\section{Introduction}

Free radical reactions of organic substances adsorbed on porous solids are of particular interest from the perspective of both materials science and heterogeneous catalysis. High surface area oxides e.g. zeolites, alumina, aluminosilicalites or higher-order oxides are attractive materials in numerous applications in catalysis. Previous research has shown that those materials play a significant role in the separation and stabilization of various reactive intermediates as atoms, radicals, radical ions, and clusters [1-7]. Studies of such intermediates are very important for a better understanding of the mechanisms of chemical reactions in polymerization, heterogeneous catalysis, photochemistry, and radiation chemistry and biology. However, in comparison with the reactions in the gas or the liquid phase the corresponding processes in such systems are less well understood.

A number of experimental techniques has been applied to the characterization of the bonding interactions between the adsorbed vinyl monomers and the surface of catalysts. The early studies of radiation induced radical polymerization have focused on the graft polymerization on the solid supports. These early results showed that only free radicals in the track of fast electrons were able to initiate polymerization process [8-10].

Due to the well defined structure, acidic and ion-exchange properties, thermal and chemical stability, microporous natural and synthetic zeolites have been considered more recently as catalytic systems for controlled polymerization. Studies of vinyl ethers adsorbed on acidic mordenite [11] and faujasite (H-Y) [12] have shown that adsorbed monomers react near room temperature to produce low molecular weight polymers. It has also been found that monomers migrate to the catalyst-polymer interface and polymerize there. Thermogravimetric analyses of zeolites and polymer composites showed that only a very small fraction of the polymer can be 
found inside the zeolite channels of mordenite while in faujasite with larger pore size the amount of polymer is significant $[11,12]$.

Electron paramagnetic resonance (EPR) and nuclear magnetic resonance (NMR) studies of radiation induced postpolymerization of acronitrile (AN) and methyl methacrylate (MMA) adsorbed on zeolite $13 \mathrm{X}$ show that overall postpolymerization kinetics may be accounted for by assuming an exponential decay of radical propagation and recombination reactions [13]. Studies of methylacetylene (MA) gas reaction in acid forms of the mordenite, omega, L, Y, beta, ZSM-5 and SAPO-5 molecular sieves indicate that MA reacts with acid sites of zeolites and forms large, conjugated polymeric species within the zeolites channels [14].

Since the MCM-41 mesoporous silica (with a hexagonal arrangement of the pores with 2-5 nm diameter) was invented at the beginning of the 1990's [15-17], applications of mesoporous molecular sieves in controlled polymerization have attracted much attention $[18,19]$. In contrast to zeolites these materials have the ability to encapsulate relatively large molecules.

Radical polymerization of MMA with benzoyl peroxide within the uniform channels of the mesoporous silica MCM-41 gives poly(methyl methacrylate) (PMMA) with a much higher molecular weight compared to those obtained in solution under identical conditions [20]. Polymerization of MMA catalyzed by samarocene complex supported on a series of mesoporous molecular sieves with various pores size provide highly syndiotactic PMMA's. Compared to polymerization in solution, polymerization of MMA in mesoporous silica provides PMAA with higher molecular weight [21].

MCM-41 along with HY zeolite has been widely used in cationic polymerization of vinyl monomers. Polymerization of vinyl monomers can be initiated by acidic protons in the $\mathrm{H}$-form of the zeolite or by co-adsorbed arylmethylium ions in MCM-4 silica [22]. In order to control 
polymerization reactions, the surface of the MCM-41 mesoporous silica can be modified (functionalized) with different organic groups [23].

Amorphous silica is one of the most common supports in catalysis and was the subject of several experimental studies during the past decades $[4,5,24]$. Silica gel support systems are widely used in studies of transition metal ions or complexes [25] and are successfully applied in controlled polymerization [26] and in studies of ionic radicals [27,28]. High resolution of the EPR spectra indicated a high degree of mobility for benzene cation radicals in an adsorbed layer.

Here we present EPR studies of radicals formed by H-atom addition to vinyl monomers adsorbed on amorphous silica surface. The understanding of the experimental results was supported by DFT calculations of hyperfine splitting constants of radicals formed from the vinyl monomers adsorbed on the silica surface, adapting a previous procedure [29]. The formation of a propagating radical in methylmetacrylate was investigated theoretically as well as experimentally.

\section{Experimental}

Sample preparation: Silica gel with a specific surface area of $667 \mathrm{~m}^{2} / \mathrm{g}$ determined by the BET method was obtained commercially (AB Kebo, Stockholm). The main impurities determined by spectral analysis were $\mathrm{Al}(350 \mathrm{ppm})$ and $\mathrm{Fe}(136 \mathrm{ppm})$. Further treatment by reflux boiling in $\mathrm{D}_{2} \mathrm{O}$ was employed in some experiments in order to replace the hydrogen atoms of surface silanol groups with deuterium [30]. Methyl methacrylate (MMA) and styrene (ST) were distilled after removing the stabilizer just before use. All other chemicals, obtained from Fluka AG, were used as received. The silica gel samples were placed in $4 \mathrm{~mm}$ EPR sample tubes made of Suprasil quartz and dehydrated at $500{ }^{\circ} \mathrm{C}$ for 17 hours in vacuo to a final pressure below $0.01 \mathrm{~Pa}$. 
Additives of previously degassed vinyl monomers in the range 1-5 weight $\%$ were then vacuumdistilled onto the silica gel as described previously [28]. The samples were sealed under vacuum and irradiated with ${ }^{60} \mathrm{Co} \gamma$-rays to a dose of $34 \mathrm{kGy}$ at $77 \mathrm{~K}$.

EPR measurements The EPR spectra were recorded at X-band, using a solution of Fremy's salt for magnetic field calibration[31]. The $g$-factors were determined relative to $g=2.0036$ of DPPH kept in a double cavity together with the sample under investigation. Measurements at higher temperatures were made by warming the samples in a variable temperature accessory attached to the EPR spectrometer.

Simulations: The experimental spectra were analysed by previously described software $[32,33]$ modelled after the classical program by Lefebvre and Maruani for the calculation of EPR spectra of free radicals in amorphous systems [34]. The hyperfine couplings employed in the simulations were estimated by a combination of the data obtained from the DFT calculations reported here, and a manual stick-plot analysis.

Quantum chemistry calculations: Geometry optimization calculations for minimum energy and transition-state structures were performed using DFT theory. Isotropic and anisotropic hyperfine couplings of the radicals formed from the vinyl monomers were calculated taking into account the interaction with the silica surface, similar to the procedure used in [29]. Details regarding the used theoretical methods are presented in the Computations section. The anisotropic couplings are given in the Supplemental Information.

\section{Results and Discussion}

\section{EPR}


Radicals formed by hydrogen addition to the vinyl monomers were the main species observed by EPR after $\gamma$-irradiation at $77 \mathrm{~K}$ of the vinyl monomers adsorbed on silica gel. A correlation between the position of $\mathrm{H}$ atom addition and the free valence index [35] was observed as illustrated in Scheme 1 for styrene, using the expression due to Burkitt et al. [36] to obtain the numerical values.

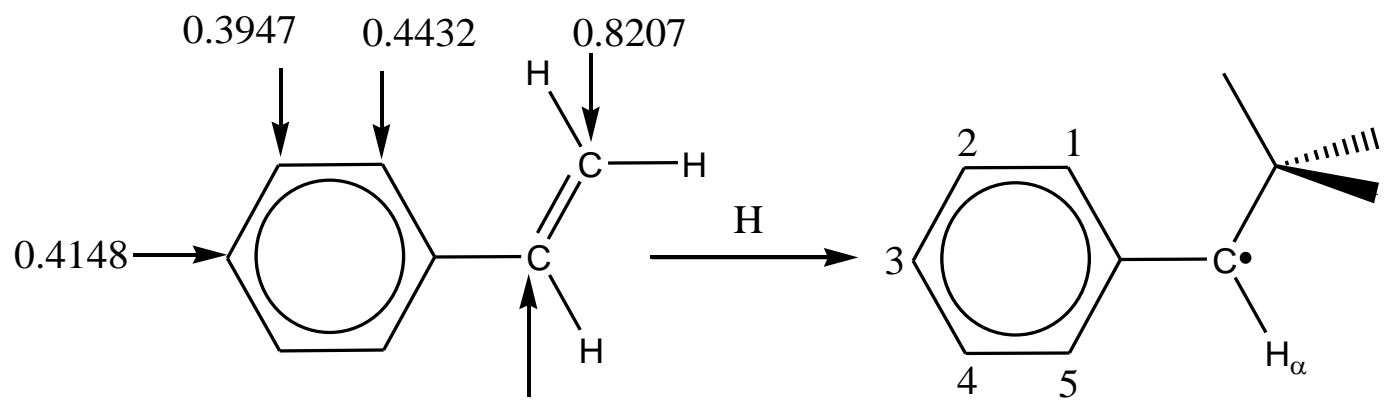

0.4148

SCHEME 1: Formation of $\mathrm{CH}_{3} \dot{\mathrm{C}}_{\alpha} \mathrm{HC}_{6} \mathrm{H}_{5}$ radical by hydrogen atom addition to styrene at the position of highest free valence index, defined by $F_{i}=\sqrt{3}-\sum_{j} P_{i j}$, [36] where $P_{i j}$ is the bond order for the $\mathrm{C}_{\mathrm{i}}-\mathrm{C}_{\mathrm{j}}$ bond in Hückel molecular orbital theory.

The isotropic hyperfine coupling constants of the spectra are given in Table 1. The g-factors were in the range 2.0023-2.0027 with an estimated uncertainty of \pm 0.0003 . The anisotropic components used in the simulations to support the assignments were taken from the DFT calculations presented in the Supplementary Information.

An EPR spectrum assigned to a propagating radical was observed at increased temperature for samples containing methyl methacrylate (MMA), but not for the other monomers. Several of the samples were colored after irradiation. It is possible that the color is caused by ionic radicals. Radical cations have previously been observed from adsorbed unsaturated compounds [37-39]. 
This possibility was only briefly considered here, however. Detailed interpretations are presented below.

Styrene/silica gel $\left(\mathbf{S T} / \mathbf{S i O}_{2}\right)$ : The EPR spectrum in Figure 1(a) recorded at $77 \mathrm{~K}$ from a $\gamma$-irradiated sample containing $5 \mathrm{wt} \%$ of styrene adsorbed on silica gel is similar to that obtained by the $\gamma$-radiolysis of $\alpha$-phenylethylchloride in 3-methylpentane glass [40]. The latter spectrum was assigned to the radical $\mathrm{CH}_{3} \dot{\mathrm{C}}_{\alpha} \mathrm{HC}_{6} \mathrm{H}_{5}$. The same radical is formed here by hydrogen atom addition to the vinyl group as shown in Scheme 1. The hyperfine structure is attributed to the $\mathrm{H}_{\alpha}$ and methyl protons. Smaller splittings of $c a .5 \mathrm{G}$ are assigned to the ring protons at positions 1,3 and 5. The splittings at positions 2 and 4 (Scheme 1) were not resolved.

Theoretical values of the anisotropic (dipolar) hyperfine splittings obtained from the DFT calculations were employed for the simulations in Figures 1(b) -1(d), while the isotropic values were slightly adjusted to obtain a satisfactory fit to the experiments. For the $\mathrm{CH}_{3}$ protons values in the range 14.5-16.5 $\mathrm{G}$ were used in the simulations, while an arithmetic average of the splittings due to $\mathrm{H}_{\beta 1} \mathrm{H}_{\beta 2}$ and $\mathrm{H}_{\beta 3}$ in Table 2 yielded theoretical values in the range 16.6-18.9 G. Similar values were derived from McConnell's relation [41] $a_{\beta}=A+B \cos ^{2} \theta$ for $\beta$-protons using the theoretical splittings $\left(a_{\beta}\right)$ and dihedral angles $(\theta)$ of the methyl protons, and assuming an averaging due to the free rotation usually occurring along the $>\mathrm{C}_{\alpha}-\mathrm{CH}_{3}$ bond in this type of radicals [42]. The anisotropy of the methyl coupling was somewhat averaged by the rotation to become axially symmetric. The isotropic splittings due to the ring protons were fixed in the simulations with the values $a_{H 1}=a_{H 3}=a_{H 5}=(-) 5 \mathrm{G}$. For the $\mathrm{H}_{\alpha}$ and $\mathrm{CH}_{3}$ protons uncertainties of the order 1-2 G of the isotropic values may occur. 
1,1-diphenyl ethylene (DPE): The analysis of the spectrum in Figure 2 (a) from a sample containing $5 \mathrm{wt} \%$ of 1,1-diphenylethylene adsorbed on silica gel $\gamma$-irradiated and recorded at 77 $\mathrm{K}$ was less straight-forward. A quartet of lines was observed as expected for the radical $\left(\mathrm{C}_{6} \mathrm{H}_{5}\right)_{2} \dot{\mathrm{C} C H} \mathrm{CH}_{3}$ formed by hydrogen atom addition to the methylene group. The observed four lines were not equidistant, however, and the relative intensity of the lines deviated from the 1:3:3:1 ratio due to the hyperfine structure of the three equivalent protons of the methyl group. Attempts to simulate the spectrum taking into account the hyperfine anisotropy of those protons and of the additional structure due to the ring protons were not successful. It seemed reasonable, however, that the two lines on the wings were due to the outer hyperfine lines of the methyl group of this radical, while the two inner lines overlapped with those of a second species. The isotropic splitting of the methyl group of the $\left(\mathrm{C}_{6} \mathrm{H}_{5}\right)_{2} \mathrm{CC}_{3}$ radical was accordingly adjusted to $a_{\mathrm{CH} 3}=16.0 \mathrm{G}$ to fit the two outer lines of the experimental spectrum. The anisotropy of this splitting and the phenyl protons were estimated by the DFT calculations presented in the Supplemental Information and taken into account in the simulations, even though the splittings of the latter protons were not resolved experimentally. The spectrum in Figure 2 (c) was additionally employed to obtain a fitting (dotted line in Figure 2 (a)) to the experimental spectrum. The assignment of this component to the DPE cation was considered, but was not supported by the DFT calculations in the Supplemental Information. The signals decayed around $250 \mathrm{~K}$ without changing the line shape.

$\alpha$-Methyl styrene (AMST) and $\beta$-methyl styrene (BMST): The resolution of the spectra from samples of $\alpha$-methyl styrene (AMST) and $\beta$-methyl styrene (BMST) shown in the Supplementary Information (Figure 1S) was relatively poor, in part attributed to the overlap with radiation induced EPR signals in silica gel [43]. 
The EPR spectrum from a sample containing $3 \%$ AMST was attributed to the radical $\left(\mathrm{CH}_{3}\right)_{2} \dot{\mathrm{C}}_{6} \mathrm{H}_{5}$ superimposed on a broad background. The isotropic splitting, $a_{\mathrm{CH} 3}=15.0 \mathrm{G}$, estimated from a stickplot analysis deviated only slightly from the values 15.8-17.9 $\mathrm{G}$ derived from the DFT calculations in Table 4. Rapid rotation about the $>\dot{\mathrm{C}}-\mathrm{CH}_{3}$ bond was assumed. The isotropic splittings of the phenyl proton of (-)5 G also agreed quite well with the corresponding calculated values. The agreement thus supports the assignment to the $\left(\mathrm{CH}_{3}\right)_{2} \dot{\mathrm{CC}}_{6} \mathrm{H}_{5}$ radical formed by $\mathrm{H}$ atom addition to the vinyl group of $\alpha$-methyl styrene. The obtained constants might, however, be less accurate than for the styrene case due to the influence of the background signal on the shape of the spectrum. A simulation is shown in the Supplemental Information.

The EPR spectrum from a sample containing $3 \%$ BMST shown in the Supplemental Information was attributed to the radical $\mathrm{CH}_{3} \mathrm{CH}_{2} \dot{\mathrm{C}}_{\alpha} \mathrm{HC}_{6} \mathrm{H}_{5}$ radical superimposed on the EPR signals present in the $\gamma$-irradiated silica gel. According to this interpretation the observed splittings of $4 \mathrm{G}$ is attributed to the ring protons, while the overall width of $c a .80 \mathrm{G}$ is accounted for by the hyperfine splittings with one $\mathrm{H}_{\alpha}$ and two $\mathrm{H}_{\beta}$ protons. According to a previous analysis one of the $\beta$ protons has a hyperfine splitting twice as large as that of the other $\beta$-proton and the $\alpha$-proton [44]. The good agreement between the hyperfine splittings obtained from the stickplot analysis reproduced in the Supplemental Information with those obtained by DFT calculations supports the assignment. Attempts to obtain more precise values for the splittings by simulations were unsuccessful. Unequal $\beta$-proton splittings may also occur in the radical $\mathrm{CH}_{3} \dot{\mathrm{C}}_{\alpha} \mathrm{HCH}_{2} \mathrm{C}_{6} \mathrm{H}_{5}$. This alternative with hydrogen atom addition at the $\beta$-position of the vinyl group was considered less likely, however, since the DFT calculations of this species could not account for the observed 4 G splitting attributed to the ring protons. It is therefore concluded that free radical formation 
occurs by hydrogen atom addition at the position of highest free valence index in this case as well.

Methyl methacrylate (MMA): The EPR spectrum from a sample containing 3 wt\% MMA adsorbed on silica gel $\gamma$-irradiated and recorded at $77 \mathrm{~K}$, Figure 3 (a), has seven equidistant lines split by $22 \mathrm{G}$. The spectrum was assigned to the radical $\left(\mathrm{CH}_{3}\right)_{2} \dot{\mathrm{CCOOCH}}$. Similar spectra have been observed in pure irradiated MMA and PMMA [45-47]. The radiation induced reactions are similar, the main net reaction at $77 \mathrm{~K}$ being a hydrogen atom addition to the vinyl group. It was observed, however, that the atoms that take part in the reaction originate mainly from the hydroxyl groups on the surface of the silica gel. This was verified by an experiment in which a sample of MMA adsorbed on deuterated silica gel was irradiated. Figure 3 (b) shows the spectrum obtained from this system. It is composed of the ordinary 7-line spectrum due to $\left(\mathrm{CH}_{3}\right)_{2} \dot{\mathrm{C} C O O C H} 3$ and a 6-line structure with a splitting constant of $22 \mathrm{G}$. The 6-line spectrum is assigned to the radical $\mathrm{CDH}_{2} \dot{\mathrm{C}}\left(\mathrm{CH}_{3}\right) \mathrm{COOCH}_{3}$. The five methyl protons give rise to the sextet, while the hyperfine structure of the added deuterium atom is too small to be resolved. The sextet spectrum (b)-(a) in Figure 3 was obtained by subtracting (a) from (b). The D atoms used in the formation of this radical originate from deuterated -OD silanol groups on the surface of the adsorbent. There might be two reasons for the observation of the 7-line spectrum at the same time. Firstly, the deuteration of the silica gel might not be complete and secondly $\mathrm{H}$ atoms can also be formed by the radiolysis of the monomer as indicated by the observation of the 7-line spectrum in irradiated pure MMA [45-47].

Radical reactions: The MMA spectrum observed at $77 \mathrm{~K}$ changed to the 9 line pattern in Figure 4 at 123 K. Similar irreversible changes have been observed for example in the benzoyl peroxide (BPO)-initiated polymerization of MMA in frozen aromatic solvents [48]. The nine lines, 
designated as the $5+4$ lines were assigned to the propagating radical $-\mathrm{CH}_{2} \dot{\mathrm{C}}\left(\mathrm{CH}_{3}\right) \mathrm{R}$. Details about the radical were obtained from the shape of the spectrum, especially the relative intensity of the lines which has been interpreted in terms of various factors such as that there is more than one conformation [49], there is a distribution of dihedral angles for a single conformation [45] or a site exchange motion around the $-\mathrm{CH}_{2}-\dot{\mathrm{C}}<$ bond [50]. Analysis of EPR spectra of PMMA radicals measured at different conversion indicated a conformational change with the chain length. Spectra attributed to a very short PMMA chain probably consisting of the initiating radical and one monomer unit were observed [51].

The spectrum observed in this work at increased temperature can be accounted for by the attachment of the initial radical $\left(\mathrm{CH}_{3}\right)_{2} \dot{\mathrm{C} C O O C H} 3,(\mathrm{R})$, to the vinyl group of MMA forming a secondary radical with the structure $\mathrm{RC}_{\beta} \mathrm{H}_{2} \dot{\mathrm{C}}_{\alpha}\left(\mathrm{CH}_{3}\right) \mathrm{COOCH}_{3}$. EPR spectra of this type of radicals observed in the solid phase with hyperfine splittings $a_{\mathrm{CH} 3}=22.2 \mathrm{G}$ to the methyl protons and $a_{\beta 1}=14.7 \mathrm{G}, a_{\beta 2}=7.5 \mathrm{G}$ of the methylene group [50] are very similar to that in Figure 4 (b). The theoretical values, obtained by the DFT calculations in the Computation section (Table 6) also support the assignment. Thus, values in the range $19.0-21.9 \mathrm{G}$ were predicted for the splitting of the methyl protons, assuming free rotation about the $\mathrm{C}_{\alpha}-\mathrm{CH}_{3}$ bond in this type of radicals [45]. Different splittings of the two $\beta$-protons were also predicted, in agreement with the experiments.

According to Figure 5 (c) a rigid structure of the radical cannot account for the selective broadening of certain lines in the experimental spectrum. Better agreement was obtained by considering an internal motion that exchanged the $a_{\beta 1}$ and $a_{\beta 2}$ splittings between 7.5 and $14.7 \mathrm{G}$ at a rate of ca. $30 \mathrm{MHz}$. A simulation taking account of the chemical exchange with the program ESREXN [52] is shown in Figure 5 (b). Rate constants of the same order were obtained from the 
observed EPR spectra of methacrylic acid radicals in frozen solution [50]. Good agreement between experimental and simulated spectra has also been achieved by assuming a distribution of conformations of the methylene group [45]. Irrespective of the detailed mechanism of the broadening the 9 line spectrum in Figure 5 (a) can safely be attributed to a radical of the type R$\mathrm{CH}_{2} \dot{\mathrm{C}}\left(\mathrm{CH}_{3}\right) \mathrm{COOCH}_{3}$, i.e. either the dimeric species predicted by the DFT calculations given below or a polymer radical with a similar local geometry about the radical site.

\section{Computations}

Geometry optimization: Geometry optimization calculations for minimum energy and transition-state structures were performed using DFT theory. Calculations were carried out using the hybrid meta GGA exchange-correlation functional M05-2X with a double fraction of Hartree-Fock exchange developed by Zhao and Truhlar [53]. According to literature data this functional performs very well in DFT studies of the adsorption of hydrocarbons on a large 16T zeolite model cluster [54,55] or modeling of water-zeolite interaction [56].

All geometries presented here were optimized with the LANL2DZ [57-59] basis set for silicon atoms and the 6-31G(d) [60] basis set for carbon, oxygen and hydrogen atoms. Effects of hybrid functional and basis sets (including $6-31+\mathrm{G}(\mathrm{d}, \mathrm{p})$ were initially tested on the $\mathrm{AMST} / \mathrm{SiO}_{2}$ model. We found no significant difference in structural parameters between M05-2X/6-31G(d) and M05-2X/6-31+G(d,p), however. The C-H bond lengths were for example1.08201 $\AA$ for 6-31G(d) and $1.08254 \AA$ for $6-31+\mathrm{G}(\mathrm{d}, \mathrm{p})$, while the the $\mathrm{O}-\mathrm{H}$ bonds in the silica cluster were $0.96393 \AA$ and $0.96073 \AA$ Å, respectively. 
Silica Model: The adsorption site of a hydroxylated amorphous silica surface was represented by a molecular cluster terminated with -OH silanol groups. As shown in Figure 6 the molecular cluster of $\mathrm{SiO}_{2}$ consists of $8 \mathrm{~T}$ (tetrahedral) sites. The cluster was fully optimized (without any restrictions) with the M05-2X functional and LANL2DZ basis set for silicon atoms and 6-31G(d) basis set for hydrogen and oxygen atoms. The calculated O-H distances are $0.96 \AA$ which is in a very good agreement with literature data [61]. The Si-O bond lengths are $1.64 \AA$ and $\mathrm{Si}-\mathrm{O}-\mathrm{Si}$ angles are in the range of $143-150^{\circ}$.

Hyperfine coupling constants: The proton hyperfine splitting constants (hfsc's) were calculated for the radicals formed by the addition of a hydrogen atom to the adsorbed vinyl monomers. The atom originates from the cleavage of a silanol bond. A hydrogen-loss ${ }^{\circ} \mathrm{O}-\mathrm{Si} \equiv$ radical center is then also formed in the $8 \mathrm{~T}$ cluster. Calculations of hfsc's were carried out in single-point runs with a combination of M05-2X and B3LYP [62] functionals and with 6-31G(d) or EPR-III [63] basis sets. The best overall agreement between experimental and calculated values was obtained for the B3LYP hybrid functional and EPR-III basis sets combination. This approach has been proven to give reliable results for the $\mathrm{Ag}\left(\mathrm{C}_{2} \mathrm{H}_{4}\right)_{2}$ or $\mathrm{Na}^{+}{ }^{\cdots} \mathrm{CH}_{3}$ complexes stabilized in SAPO-11 molecular sieve and 4A zeolite, respectively [64,65].

All calculations presented here were performed using the Gaussian 09 package [66]. Since most of the experimentally observed EPR spectra had an isotropic appearance, only isotropic hfsc's are listed in the tables. The anisotropic values of the hfsc's obtained in the calculations are presented in the Supplemental Information, however.

\section{Radical structures and hyperfine coupling constants}


ST/SiO 2 : Figure 7 shows the optimized structure of the styrene (ST) radical adsorbed on the hydroxylated surface of silica gel represented here by the $8 \mathrm{~T}$ molecular cluster. Selected structural parameters are also shown in Figure 7. The most stable conformation of the styrene radical adsorbed on the silica surface interacts via $\mathrm{H}_{\alpha}$ with the nearest oxygen atom and via $\mathrm{C}_{6}$ of the aromatic ring with the $\mathrm{H}$ atom of a silanol group. The calculated distance $\mathrm{C}_{6} \cdots \mathrm{H}-\mathrm{O}$ - was found to be $2.41 \AA$ and the hydrogen-bond distance between $\mathrm{H}_{\alpha}$ and the nearest oxygen atom of the silica cluster was $2.83 \AA$. Such long distances between silica and the ST radical indicate very weak interaction of the adsorbate molecule with the $\mathrm{SiO}_{2}$ surface. The calculated adsorption energy (total energy relative to the isolated $8 \mathrm{~T}$ cluster and the ST radical) was found to be 6.8 $\mathrm{kcal} \cdot \mathrm{mol}^{-1}$.

The interaction of the ST radical with a silanol group results in slight $\mathrm{O}-\mathrm{H}$ bond elongation to $0.97 \AA$ compared to $0.96 \AA$ in the isolated cluster. The bond lengths of the adsorbed radical remained unchanged compared to the isolated radical (gas phase). The radical optimized with a silica cluster is slightly twisted $\left(1^{\circ}\right)$ along the $\mathrm{C}_{\alpha}-\mathrm{C}_{6}$ bond, however. The calculated $\mathrm{C}-\mathrm{H}$ bonds distances have values of $1.08-1.10 \AA$, and $\mathrm{C}_{\alpha}-\mathrm{C}_{\beta}$ and $\mathrm{C}_{\alpha}-\mathrm{C}_{6}$ bond distances are 1.49 and $1.42 \AA$, respectively. All structural parameters of the aromatic ring are in a very good agreement with the geometry of benzene adsorbed on various types of zeolites [67].

Calculated isotropic hyperfine splitting constants for the $\mathrm{ST}$ radical adsorbed on the $\mathrm{SiO}_{2}$ surface are listed in Table 2. The isotropic $\mathrm{H}_{\alpha}$ hfsc's calculated with the M05-2X/6-31G(d) and B3LYP/6-31G(d) methods are -18.40 and $18.04 \mathrm{G}$ respectively. Lower values were obtained with M05-2X/EPR-III and B3LYP/EPR-III methods and are -12.50 and -15.49 G. Compared to the value $-16.5 \mathrm{G}$ used in the simulation of the experimental spectrum all used methods give 
reasonable $\mathrm{H}_{\alpha}$ splittings. However, the closest value was obtained with the B3LYP/EPR-III method. The calculated average $\left(a_{\mathrm{H} \beta 1}+a_{\mathrm{H} \beta 2}+a_{\mathrm{H} \beta 3}\right) / 3$ of the isotropic $\mathrm{H}_{\beta}$ hyperfine splitting constants varied from $16.55 \mathrm{G}$ for M05-2X/EPR-III to $18.87 \mathrm{G}$ for the B3LYP/ EPR-III method. Also the hyperfine splitting constants of the aromatic protons of $\mathrm{H}_{1}, \mathrm{H}_{3}$ and $\mathrm{H}_{5}$ strongly depended on the method and were in the range of $-3.58-(-) 5.77 \mathrm{G}$. Much lower couplings, 1.01-2.33 $\mathrm{G}$ were obtained for the aromatic protons $\mathrm{H}_{2}$ and $\mathrm{H}_{4}$, supporting the experimental assignment. The best agreement with experiments was obtained with the B3LYP/EPR-III method. The M05-2X/EPR-III method gives slightly underestimated values of the calculated hyperfine splittings.

DPE/SiO 2 : The optimized geometry of the DPE radical adsorbed on the $\mathrm{SiO}_{2}$ surface is shown in Figure 8. Compared to the isolated DPE radical, only small changes in the $\angle\left(\mathrm{C}_{\beta}-\mathrm{C}_{\alpha}-\mathrm{C}_{1}-\mathrm{C}_{2 \mathrm{a}}\right)$ and $\angle\left(\mathrm{C}_{\beta}-\mathrm{C}_{\alpha}-\mathrm{C}_{1}-\mathrm{C}_{2 \mathrm{~b}}\right)$ dihedral angles were observed. Similar to the other radicals in this study the DPE radical interacts with the $\mathrm{SiO}_{2}$ surface via a $\mathrm{C}$ atom of one of the aromatic rings and the $\mathrm{H}_{\beta}$ atom. The calculated distances are 2.54 and $2.56 \AA$ respectively. The calculated adsorption energy was found to be slightly higher compared to the smaller radicals and is $11.36 \mathrm{kcal} \cdot \mathrm{mol}^{-1}$.

Calculated hyperfine splitting constants for the DPE radical are listed in Table 3. As expected the $\mathrm{CH}_{3}$ group exhibits the largest hyperfine splittings. The average isotropic constants $\left(a_{\mathrm{H} \beta 1}+a_{\mathrm{H} \beta 2}+a_{\mathrm{H} \beta 3}\right) / 3$ depended on the calculation method and were in the range of $15.41-16.58 \mathrm{G}$ compared to the experimental $16.0 \mathrm{G}$. All $\mathrm{H}_{\beta}$ protons also exhibit small anisotropy and this was taken into account in the simulation of the experimental EPR spectrum of the DPE radical. The calculated hyperfine splitting constants of the phenyl protons, not resolved in the experimental EPR spectrum of DPE, are $-1.73-(-) 4.23 \mathrm{G}$ for $\mathrm{H}_{1}, \mathrm{H}_{3}, \mathrm{H}_{5}$ and $0.84-2.73 \mathrm{G}$ for $\mathrm{H}_{2}, \mathrm{H}_{4}$. 
AMST and BMST radicals: Figures 9 (a) and (b) illustrate the M05-2X/6-31G(d) optimized geometries of the AMST and BMST adsorption complexes, respectively. Similar to the ST radical both AMST and BMST interact with the silica surface through the $\mathrm{C}$ atom located in the aromatic ring and through the hydrogen bond between one of the $\mathrm{H}_{\beta}$ and the ${ }^{\circ} \mathrm{O}-\mathrm{Si} \equiv$ radical center. The calculated distance between $\mathrm{C}_{1}$ of the AMST radical and the silanol proton was found to be $2.40 \AA$ compared to $2.41 \AA$ calculated for the ST radical. The H-bond distance between oxygen and $\mathrm{H}_{\beta}$ of the $\mathrm{CH}_{3}$ group $(\equiv \mathrm{Si}-\mathrm{O} \cdots \mathrm{H}-\mathrm{C})$ was $2.79 \AA$. Compared to the isolated AMST radical, the $-\mathrm{CH}_{3}$ groups of a radical adsorbed on the silica surface are about $6^{\circ}$ out of plane of the molecule (dihedral angle $\left.\angle\left(\mathrm{C}_{\beta}-\mathrm{C}_{\alpha}-\mathrm{C}_{1-} \mathrm{C}_{2}\right)=6.2^{\circ}\right)$. The bond lengths in the aromatic (phenyl) ring are in the same range as in the ST radical.

The interaction of the AMST radical with the silica surface leads to slight bond elongations in the $8 \mathrm{~T}$ cluster. The calculated $\mathrm{O}-\mathrm{Si} \equiv$ bond length is $1.66 \AA$ and the $\mathrm{O}-\mathrm{H}$ bond in the silanol group is $0.97 \AA$. The calculated adsorption energy for the $\mathrm{AMST} / \mathrm{SiO}_{2}$ system was found to be 8.7 $\mathrm{kcal} \cdot \mathrm{mol}^{-1}$ indicating a very weak interaction of the AMST radical with the silica surface like for the ST radical.

Similar to the AMST/SiO 2 system the shortest radical to cluster distance in the $\mathrm{BMST} / \mathrm{SiO}_{2}$ system was found between the $\mathrm{H}$ atom of silanol and $\mathrm{C}_{4}$. The calculated distance was $2.41 \AA$. The hydrogen-bond distance between oxygen and $\mathrm{H}_{\beta 2}$ of the methylene group ( $\left.\equiv \mathrm{Si}-\mathrm{O} \cdots \mathrm{H}-\mathrm{C}\right)$ is shorter compared to the AMST and ST systems and was found to be $2.64 \AA$. As seen in Figure 9 (b) the BMST radical is twisted along $\mathrm{C}_{\alpha}-\mathrm{C}_{\beta}$. The calculated dihedral angle $\angle\left(\mathrm{C}_{\gamma}-\mathrm{C}_{\beta}-\mathrm{C}_{\alpha}-\mathrm{C}_{1}\right)$ is $14.1^{\circ}$. Adsorption on the silica surface does not affect the geometry of the phenyl ring and all 
bond distances are in the same range as in the ST and AMST radicals. This radical also weakly interacts with the $\mathrm{SiO}_{2}$ surface. The calculated adsorption energy was $10.9 \mathrm{kcal} \cdot \mathrm{mol}^{-1}$.

Calculated hyperfine splitting constants for both the $\mathrm{AMST} / \mathrm{SiO}_{2}$ and the $\mathrm{BMST} / \mathrm{SiO}_{2}$ systems are listed in Table 4. The isotropic hyperfine splitting constant of the six equivalent $\mathrm{H}_{\beta}$ protons in the AMST radical is very close to the experimental value. The values depend on the method, however, and vary from 15.8 G for M05-2X/EPR-III, $16.55 \mathrm{G}$ for M05-2X/6-31G(d), $17.49 \mathrm{G}$ for B3LYP/6-31G(d) and $17.95 \mathrm{G}$ for B3LYP/EPR-III. The largest hyperfine splitting constants of the phenyl protons were obtained for $\mathrm{H}_{1}, \mathrm{H}_{3}$ and $\mathrm{H}_{5}$ and are in the range of $-3.24-(-5.37) \mathrm{G}$, while the splittings of $\mathrm{H}_{2}$ and $\mathrm{H}_{4}$ are in the range of 0.94-2.11 G. All these values are in very good agreement with the experimental ones and support the interpretation of the experimental spectrum.

MMA/SiO 2 : The most stable geometry of the MMA radical adsorbed on the $\mathrm{SiO}_{2}$ surface is illustrated in Figure 9. The radical is adsorbed via interactions of the $\mathrm{C}=\mathrm{O}$ group with the hydrogen atom of a silanol group and between one of the $\mathrm{H}_{\beta}$ atoms and oxygen on the silica surface. The calculated distances $\mathrm{C}=\mathrm{O} \cdots \mathrm{HO}-\mathrm{Si} \equiv$ and $\mathrm{H}_{\beta} \cdots \mathrm{O}-\mathrm{Si} \equiv$ are 1.79 and $2.57 \AA$ respectively. The adsorption energy is slightly higher compared to the other radicals and was found to be $12.9 \mathrm{kcal} \cdot \mathrm{mol}^{-1}$, still indicating a weak interaction with the surface of silica, however.

The calculated hyperfine splitting constants for the MMA radical are listed in Table 5. Because only $\mathrm{H}_{\beta}$ protons contribute to the experimental EPR spectrum of MMA, only these values are listed in the Table. 
MMA Polymerization: The free radical mechanism for the polymerization of vinyl monomers has recently been intensively studied theoretically. Density functional calculations of the Mayo and Flory mechanisms for the self-initiation of styrene polymerization showed that hydrogen atom transfer generates two radical species. This was predicted to be a reasonable process that initiates MMA polymerization [68]. Zhang et al. have investigated the mechanism of the spontaneous initiation of the MMA polymerization. Six possible reaction paths were calculated at the B3LYP/6-31G level. They found that the most favorable paths supported the Flory mechanism [69]. Degirmenci et al. have applied various functionals such as BMK, BB1K, MPW1B95, MPW1K, and MPWB1K in studies of propagation kinetics [70] during free radical polymerization of $\alpha$-substituted acrylates and in the modeling of solvent effects for the polymerization of MMA [71].

In our studies the interaction of the MMA radical with the surface of $\mathrm{SiO}_{2}$ is rather weak and for computational reason and for simplicity the polymerization reaction of MMA was therefore investigated in the gas phase only. The transition state for the free radical polymerization of MMA was localized by employing the linear synchronous transit followed by quadratic synchronous transit algorithm [72,73]. Additionally, a transition structure (TS) was checked by IRC (intrinsic reaction coordinate) calculations [74].Single point energies were calculated at M05-2X/6-311+G(2df,p) level of theory. The transition state structure was characterized by only one imaginary frequency.

The polymerization reaction is initiated by the hydrogen atom transfer from the silanol group to the adsorbed MMA molecule. The formed radical can then attack the double bond of the monomer. The formation of the dimeric radical species depends on the relative orientations of the monomer radical and the MMA monomer [71]. Figure 11 shows the potential energy surface 
and geometries of MMA, the monomer radical, $\left(\mathrm{CH}_{3}\right)_{2} \dot{\mathrm{C} C O O C H} 3(\mathrm{R})$, and the dimer radical, $\mathrm{RC}_{\beta} \mathrm{H}_{2} \dot{\mathrm{C}}_{\alpha}\left(\mathrm{CH}_{3}\right) \mathrm{COOCH}_{3}$, computed at the M05-2X/6-311+G(2df,2p)//M05-2X/6-31G(d) level of theory. In the transition structure the $\mathrm{C} \cdots \mathrm{C}$ distance between the radical and the monomer unit is $2.27 \AA$ in good agreement with the value calculated at the MPWB1K/6$311+\mathrm{G}(3 \mathrm{df}, 2 \mathrm{p}) / / \mathrm{B} 3 \mathrm{LYP} / 6-31+\mathrm{G}(\mathrm{d})$ level in a study of the polymerization of MMA in methanol [71]. The calculated activation energy of $8.6 \mathrm{kcal} \cdot \mathrm{mol}^{-1}$ is slightly higher, however, compared to the values obtained in the presence of solvent molecules. The activation energy was unfortunately not determined experimentally.

The calculated hyperfine splitting constants for the PMMA radical are listed in Table 6. Because of the small anisotropy only isotropic splittings are presented. The average value $a_{\mathrm{CH} 3(\mathrm{av})}=21.85$ G, calculated by the B3LYP/EPR-III method agrees well with the experimental splitting, supporting the assignment, while the other methods predict slightly too low splitting. The values for $a_{\beta 1}$ and $a_{\beta 2}$ deviate somewhat from the splittings $14.7 \mathrm{G}$ and $7.5 \mathrm{G}$ obtained experimentally. This may be due to difficulties in estimating those values in the presence of chemical exchange (Figure 5 (b)), inaccuracies in the theory or a combination of both.

\section{Conclusions}

Radicals formed by hydrogen atom addition, preferably to the carbon atom with highest free valence index, were the main species identified by EPR after $\gamma$-irradiation at $77 \mathrm{~K}$ of several vinyl monomers adsorbed on silica gel. Experiments with deuterated silica showed that the hydrogen atoms originated from the surface silanol groups of the silica gel. 
The structures of the adsorption complexes were modeled and the adsorption energies were calculated applying DFT quantum chemical methods. Calculated hyperfine splitting constants at various levels of theory verified the assignment of the experimental EPR spectra. The best overall agreement with experimental values was obtained with a combination of the B3LYP hybrid functional and the EPR-III basis set.

A polymerization reaction was observed in the MMA/silica gel system. Based on the experimental EPR spectra alone, it is impossible to determine the chain length of the formed PMMA radical. Gas phase DFT calculations at the M05-2X/6-311+G(2df,2p)//M05-2X/6$31 \mathrm{G}(\mathrm{d})$ level gives an activation barrier of $8.6 \mathrm{kcal} \cdot \mathrm{mol}^{-1}$ for the first step in the free radical polymerization mechanism of MMA. The close agreement between the calculated hyperfine couplings of the formed dimeric radical and the experimental ones may indicate a short chain length under the experimental conditions.

\section{References}

[1] P. H. Kasai, Electron spin resonance studies of vinyl, propargyl, and butatrienyl radicals isolated in argon matrices, J. Am. Chem. Soc. 94 (1972) 5950-5956.

[2] M. Danilczuk, A. Lund, Adsorption of NO in Li-exchanged zeolite LTA. A density functional theory study, Chem. Phys. Lett. 490 (2010) 205-209.

[3] M. Danilczuk, D. Pogocki, A. Lund, Interaction of $\mathrm{CH}_{2} \mathrm{OH}$ with silver cation in AgA/ $\mathrm{CH}_{3} \mathrm{OH}$ zeolite: A DFT study, Chem. Phys. Lett. 469 (2009) 153-156.

[4] T. Shiga, A. Lund, g-Factor and hyperfine coupling anisotropy in the electron spin resonance spectra of methyl-, ethyl, and allyl-type radicals adsorbed on silica gel, J. Phys. Chem. 77 (1973) 453-455.

[5] T. Komatsu, A. Lund, P-O. Kinell, Electron spin resonance studies on irradiated heterogeneous system VIII Radical cation formation from toluene, J. Phys. Chem. 76 (1972) 1721-1726. 
[6] T. Archipov, S. Santra, A. B. Ene, H. Stoll, G. Rauhut, E. Roduner, Adsorption of benzene to copper in CuHY zeolite J. Phys. Chem. C 113 (2009) 4107-4116.

[7] G. Hübner, E. Roduner, ESR observation of redox processes on benzene-loaded NaPdY, NaPtY and NaCeY zeolites, Magn. Reson. Chem. 37 (1999) 23-26.

[8] J. Fock, A. Henglein, W. Schnabel, The effects of linear energy transfer in the radiationinduced polymerization of several vinyl compounds, J. Phys. Chem. 68 (1964) 310-314.

[9] K. Fukano, E. Kageyama, Study on radiation-induced polymerization of vinyl monomers adsorbed on inorganic substances. I. Radiation-induced polymerization of styrene adsorbed on several inorganic substances, J. Polym. Sci. Polym. Chem. Ed. 13 (1975) 1309-1324.

[10] K. Fukano, E. Kageyama, Radiation-induced polymerization of vinyl monomers adsorbed on inorganic substances. VI. Temperature dependence and effects of additives on methyl methacrylate-silica gel system, J. Polym. Sci. Polym. Chem. Ed. 14 (1976) 1031-1041.

[11] R. M. Barrer, A. T. T. Oei, Polymerization with zeolite catalysts : I. Polymerization of nbutylvinylether by H-mordenite, J. Catal. 30 (1973) 460-466.

[12] R. M. Barrer, A. T. T. Oei, Polymerization with zeolite catalysts : II. Vinyl ethers over Hmordenite and H-Y, J. Catal. 34 (1974) 19-28.

[13] J. P. Quaegebeur, T. Seguchi, H. L. Bail, C. Chachaty, ESR and NMR study of the $\gamma$-rayinduced postpolymerization of vinyl monomers adsorbed on zeolite, J. Polym. Sci. Polym. Chem. Ed. 14 (1976) 2703-2724.

[14] S. D. Cox, G. D. Stucky, Polymerization of methylacetylene in hydrogen zeolites, J. Phys. Chem. 95 (1991) 710-720.

[15] J. S. Beck, J. C. Vartuli, W. J. Roth, M. E. Leonowicz, C. T. Kresge, K. D. Schmitt, C. T. W. Chu, D. H. Olson, E. W. Sheppard, A new family of mesoporous molecular sieves prepared with liquid crystal templates, J. Am. Chem. Soc. 114 (1992) 10834-10843.

[16] C. T. Kresge, J. C. Vartuli, W. J. Roth, M. E. Leonowicz, The discovery of ExxonMobil's M41S family of mesoporous molecular sieves, Studies Surf. Sci. Catal. 148 (2004) 53-72.

[17] C. J. Vartuli, S. S. Shih, C. T. Kresge, J. S. Beck, Potential applications for M41S type mesoporous molecular sieves, Stud. Surf. Sci. Catal. 117 (1998) 13-21.

[18] Y. S. Ko, T. K. Han, J. W. Park, S. I. Woo, Propene polymerization catalyzed over MCM41 and VPI-5-supported Et(ind) ${ }_{2} \mathrm{ZrCl}_{2}$ catalysts, Macromol. Rapid Commun. 17 (1996) 749-758.

[19] Y. Oumi, A. Hanai, T. Miyazaki, H. Nakajima, S. Hosoda, T. Teranishi, T. Sano, In Studies in Surface Science and Catalysis Nanotechnology in Mesostructured Materials, Proceedings of the 3rd International Materials Symposium, Oumi, Y., Ed.;Elsevier, 2003; pp 753-756. 
[20] S. M. Ng, S. I. Ogino, T. Aida, K. A. Koyano, T. Tatsumi, Free radical polymerization within mesoporous zeolite channels, Macromol. Rapid Commun. 18 (1997) 991-996.

[21] X. F. Ni, Z. Q. Shen, H. Yasuda, Polymerization of Methyl Methacrylate with Samarocene Complex Supported on Mesoporous Silica, Chin. Chem. Lett. 12 (2001) 821-822.

[22] S. Spange, A. Graser, H. Muller, Y. Zimmermann, P. Rehak, C. Jager, H. Fuess, C. Baehtz, Synthesis of Inorganic/Organic Host-Guest Hybrid Materials by Cationic Vinyl Polymerization within Y Zeolites and MCM-41, Chem. Mater. 13 (2001) 3698-3708.

[23] K. Ikeda, M. Kida, K. Endo, Polymerization of Methyl Methacrylate with Radical Initiator Immobilized on the Inside Wall of Mesoporous Silica, Polym. J. 41 (2009) 672-678.

[24] T. Shiga, H. Yamada, A. Lund, Conformation and Mobility of radicals in heterogeneous systems ESR spectra at $4 \mathrm{~K}$ of Methyl, Ethyl, n-Propyl Radicals Adsorbed on Silica Gel, Z. Naturforsch. 29a (1974) 653-659.

[25] Y. Ben Taarit, J. H. Lunsford, Chem. EPR evidence for ${ }^{17} \mathrm{O}$ on molybdenum oxide supported by silica-gel, Phys. Lett. 19 (1973) 348-350.

[26] J. Stejskal, M. Trchova, S. Fedorova, I. Sapurina, J. Zemek, Surface Polymerization of Aniline on Silica Gel, Langmuir, 19 (2003) 3013-3018.

[27] O. Edlund, P. O. Kinell, A. Lund, A.Shimizu, Electron Spin Resonance Spectra of Monomeric and Dimeric Cations of Benzene, J. Chem. Phys. 46 (1967) 3679-3680.

[28] O. Edlund, P. O. Kinell, A. Lund, A.Shimizu, In R.F.Gould, Ed., Advances in Chemistry Series, Radiation Chemistry, 1968, 22, 311-326.

[29] T. Takada, H. Tachikawa, Hybrid DFT Study of the Hyperfine Coupling Constants of Methyl Radicals in Model Matrix Lattices, Int. J. Quantum Chem. 105 (2005) 79-83.

[30] H. W. Kohn, Deuterium exchange on silica gel initiated by cobalt-60 irradiation, J. Phys. Chem. 66 (1962) 1017-1021.

[31] B. L. Bales, E. Wajnberg, O. R. Nascimento, Temperature-dependent hyperfine coupling constant of the dianion radical of Fremy's salt, a convenient internal thermometer for EPR spectroscopy, J. Magn. Reson. A 118 (1996) 227-233.

[32] A. Lund, K. A. Thuomas, J. Maruani, Calculation of powder ESR spectra of radicals with hyperfine and quadrupolar interactions. Application to mono- and dichloroalkyl radicals, J. Magn. Reson. 30 (1978) 505-514.

[33] A. Lund, R. Erickson, EPR and ENDOR Simulations for Disordered Systems: The Balance Between Efficiency and Accuracy, Acta Chem. Scand. 52 (1998) 261-274.

[34] R. Lefebvre, J. Maruani, Use of computer programs in the interpretation of electron paramagnetic resonance spectra of dilute radicals in amorphous solid samples. I. High-field 
treatment. X-band spectra of pi-electron unconjugated hydrocarbon radicals, J. Chem. Phys. 42 (1965) 1480-1496.

[35] C. A. Coulson, Valence, Oxford University Press 2nd.ed. 1961.

[36] F. H. Burkitt, C. A. Coulson, H. C. Longuet-Higgins, Free valence in unsaturated hydrocarbons , Trans. Faraday Soc. 47 (1951) 553-564

[37] V. Fornes, H. Garcia, S. Jovanovic, V. Marti, 1,1-Diphenylethylene adsorbed onto acid zeolites: Nature of the blue (605-nm) species, Tetrahedron, 53 (1997) 4715-4726.

[38] J. J. Rooney, R. C. Pink, Formation and stability of hydrocarbon radical-ions on a silicaalumina surface, Trans. Faraday Soc. 58 (1962) 1632-1641.

[39] E. Roduner, R. Crockett, L. M. Wu, Hyperfine anisotropy and mobility of organic radical cations in zeolites, J. Chem. Soc., Faraday Trans. 89 (1993) 2101-2105.

[40] D. W. Skelly, R. G. Hayes, W. H. Hamill, Paramagnetic resonance of alkyl radicals from dissociative electron attachment in $\gamma$-irradiated organic glass, J. Phys. Chem. 43 (1965) 2795-2798.

[41] C. Heller, H.M. McConnell, Radiation damage in organic crystals. ii. electron spin resonance of $\left(\mathrm{CO}_{2} \mathrm{H}\right) \mathrm{CH}_{2} \mathrm{CH}\left(\mathrm{CO}_{2} \mathrm{H}\right)$ in beta-succinic acid, J. Chem. Phys. 32 (1960) 15351539.

[42] M. Iwasaki, Y. Sakai, ESR spectra of poly(methacrylic acid) and poly(methyl methacrylate): Reinterpretation of the 9-line spectrum, J. Polym. Sci. A Polym. Chem. 7 (1969) 1537-1547.

[43] P-O. Kinell, T. Komatsu, A. Lund, T. Shiga, A. Shimizu, Electron spin resonance studies on irradiated heterogeneous systems. VI. The structure and reactivity of paramagnetic centers in silica gel, Acta Chem. Scand. 24 (1970) 3265-3275.

[44] O. Edlund, P-O. Kinell, A. Lund, A. Shimizu, Electron spin resonance of irradiated heterogeneous systems. Free radical formation in vinyl monomers. Report LF-83 (1978) Swedish Research Councils' Laboratory, Studsvik.

[45] C. H. Bamford, A. D. Jenkins, M. C. R. Symons, M. G. Townsend, Trapped radicals in heterogeneous vinyl polymerization, J. Polym. Sci. 34 (1959) 181-198.

[46] S. Zhu, Y. Tian, A. E. Hamielec, D. R. Eaton, Radical trapping and termination in freeradical polymerization of methyl methacrylate, Macromolecules 23 (1990) 1144-1150.

[47] T. Gillbro, P-O. Kinell, A. Lund, ESR single crystal study of radical and radical-pair formation in some $\gamma$-irradiated vinyl monomers, J. Polym. Sci. A-2 (1971) 1495-1507.

[48] M. Kamachi, M. Kohno, D. Liaw, S. Katsuki, ESR study of the propagating radical in the polymerization of MMA in frozen state, Polymer Journal 10 (1978) 69-75. 
[49] M. Kamachi, Y. Kuwae, S. Nozakura, K. Hatada, H. Yuki, Conformation of the propagating radical of triphenylmethyl methacrylate as studied by ESR, Polymer Journal 13 (1981) 919-925.

[50] Y. Sakai, M. Iwasaki, Change with temperature of the ESR spectra of methacrylic acid radicals, J. Polym. Sci. A Polym. Chem., 7 (1969) 1749-1764.

[51] M. P. Tonge, R. J. Pace, R. G. Gilbert, Electron paramagnetic resonance investigation of the nature of the propagating species in methyl methacrylate polymerization, Macromol. Chem. Phys., 195 (1994) 3159-3172.

[52] J. Heinzer, EXREXN: Simulation of exchange-broadened isotropic ESR spectra, QCPE 11 (1972) 209.

[53] Y. Zhao, N. E. Schultz, D. G. Truhlar, Design of density functionals by combining the method of constraint satisfaction with parametrization for thermochemistry, thermochemical kinetics, and noncovalent interactions, J. Chem. Theory Comput. 2 (2006) 364-382.

[54] Y. Zhao, D. G. Truhlar, Applications and validations of the Minnesota density functional, Chem. Phys. Lett. 502 (2011) 1-13.

[55] Y. Zhao, D. G. Truhlar, Benchmark Data for Interactions in Zeolite Model Complexes and Their Use for Assessment and Validation of Electronic Structure Methods, J. Phys. Chem. C 112 (2008) 6860-6868.

[56] F. Labat, A. H. Fuchs, C. Adamo, Toward an accurate modeling of the water-zeolite interaction: calibrating the DFT approach, J. Phys. Chem. Lett. 1 (2010) 763-768.

[57] Dunning,T.H., Hay,P.J.: Modern Theoretical Chemistry. In: Modern Theoretical Chemistry. Schaefer III,H.F. (ed.),Plenum, New York 1976, pp. 1-28.

[58] P.J. Hay, W.R. Wadt, Ab initio effective core potentials for molecular calculations. Potentials for main group elements Na to Bi, J. Chem. Phys. 82 (1985) 284-298.

[59] P.J. Hay, W.R. Wadt, Ab initio effective core potentials for molecular calculations. Potentials for K to Au including outermost core orbitals, J. Chem. Phys. 82 (1985) 299310.

[60] W.J. Hehre, R. Ditchfield, J.A. Pople, Self-Consistent Molecular Orbital Methods. XII. Further Extensions of Gaussian-Type Basis Sets for Use in Molecular Orbital Studies of Organic Molecules, J. Chem. Phys. 56 (1972) 2257-2261.

[61] T. Takada, H. Tachikawa, DFT and direct ab-initio MD study on hyperfine coupling constants of methyl radicals adsorbed on model surface of silica gel, J. Mol. Catal. A:Chem 311 (2009) 54-60. 
[62] A.D. Becke, Density-functional thermochemistry. III. The role of exact exchange, J. Chem. Phys. 98 (1993) 5648-5652.

[63] N. Rega, M. Cossi, V. Barone, Development and validation of reliable quantum mechanical approaches for the study of free radicals in solution, J. Chem. Phys. 105 (1996) 1106011067.

[64] M. Danilczuk, D. Pogocki, A. Lund, J. Michalik, EPR and DFT study on the stabilization of radiation-generated methyl radicals in dehydrated Na-A zeolite J. Phys. Chem. B 110 (2006) 24492-24497.

[65] M. Danilczuk, D. Pogocki, A. Lund, J. Michalik, Interaction of silver atoms with ethylene in Ag-SAPO-11 molecular sieve: an EPR and DFT study, Phys. Chem. Chem. Phys., 6 (2004) 1165-1168.

[66] Gaussian 09, Revision B.01, M. J. Frisch, G. W. Trucks, H. B. Schlegel, G. E. Scuseria, M. A. Robb, J. R. Cheeseman, G. Scalmani, V. Barone, B. Mennucci, G. A. Petersson, H. Nakatsuji, M. Caricato, X. Li, H. P. Hratchian, A. F. Izmaylov, J. Bloino, G. Zheng, J. L. Sonnenberg, M. Hada, M. Ehara, K. Toyota, R. Fukuda, J. Hasegawa, M. Ishida, T. Nakajima, Y. Honda, O. Kitao, H. Nakai, T. Vreven, J. A. Montgomery, Jr., J. E. Peralta, F. Ogliaro, M. Bearpark, J. J. Heyd, E. Brothers, K. N. Kudin, V. N. Staroverov, T. Keith, R. Kobayashi, J. Normand, K. Raghavachari, A. Rendell, J. C. Burant, S. S. Iyengar, J. Tomasi, M. Cossi, N. Rega, J. M. Millam, M. Klene, J. E. Knox, J. B. Cross, V. Bakken, C. Adamo, J. Jaramillo, R. Gomperts, R. E. Stratmann, O. Yazyev, A. J. Austin, R. Cammi, C. Pomelli, J. W. Ochterski, R. L. Martin, K. Morokuma, V. G. Zakrzewski, G. A. Voth, P. Salvador, J. J. Dannenberg, S. Dapprich, A. D. Daniels, O. Farkas, J. B. Foresman, J. V. Ortiz, J. Cioslowski, D. J. Fox, Gaussian, Inc., Wallingford CT, 2010.

[67] R. Rungsirisakun, B. Jansang, P. Pantu, J. Limtrakul, The adsorption of benzene on industrially important nanostrictured catalysts (H-BEA, H-ZSM-5, and H-FAU): confinement effects, J. Mol. Structure 733 (2005) 239-246.

[68] K. S. Khuong, W. H. Jones, W. A. Pryor, K. N. Houk, The mechanism of the self-initiated thermal polymerization of styrene. Theoretical solution of a classic problem, J. Am. Chem. Soc. 127 (2005) 1265-1277.

[69] C. Zhang, X. Wang, L. Liu, Y. Wang, X. Peng, Modeling the spontaneous initiation of the polymerization of methyl methacrylate, J. Mol. Model. 14 (2008) 1053-1064.

[70] I. Degirmenci, V. Aviyente, V. van Speybroeck, M. Waroquier, DFT study on the propagation kinetics of free-radical polymerization of $\alpha$-substituted acrylates, Macromolecules 42 (2009) 3033-3041.

[71] I. Degirmenci, E. Sukru, V. Aviyente, B. De Sterck, K. Hemelsoet, V. van Speybroeck, M. Waroquier, Modeling the solvent effect on the tacticity in the free radical polymerization of methyl methacrylate, Macromolecules 43 (2010) 5602-5610. 
[72] C. Peng, H. B. Schlegel, Combining synchronous transit and quasi-Newton methods to find transition states, Israel J. Chem. 33 (1993) 449-454.

[73] C. Peng, P. Y. Ayala, H. B. Schlegel, M. J. Frisch, Using redundant internal coordinates to optimize geometries and transition states, J. Comp. Chem., 17 (1996) 49-56.

[74] C. Gonzalez, H. B. Schlegel, Reaction path following in mass-weighted internal coordinates, J. Phys. Chem., 94 (1990) 5523-5527. 
TABLE 1. Isotropic hyperfine splitting constants $(\mathrm{G}, 1 \mathrm{G}=0.1 \mathrm{mT})$ of radicals in $\gamma$-irradiated vinyl monomers adsorbed on the surface of silica gel.

\begin{tabular}{|l|c|c|l|l|}
\hline Adsorbate & Amount (wt\%) & Temperature (K) & Assignment & Hyperfine splitting (G) \\
\hline Styrene & 5 & 77 & $\mathrm{CH}_{3} \dot{\mathrm{C}}_{\alpha} \mathrm{HC}_{6} \mathrm{H}_{5}$ & $\begin{array}{l}a_{\alpha}=16.5 \\
a_{\mathrm{CH} 3}=16.5 \\
a_{\text {ring }}=5.0(3 \mathrm{H})\end{array}$ \\
\hline $\begin{array}{l}\text { 1,1-diphenyl- } \\
\text { ethylene }\end{array}$ & 3 & 77 & $\mathrm{CH}_{3} \dot{\mathrm{C}}_{\alpha}\left(\mathrm{C}_{6} \mathrm{H}_{5}\right)_{2}$ & $a_{\mathrm{CH} 3}=17.0$ \\
\hline $\begin{array}{l}\alpha \text {-methyl- } \\
\text { styrene }\end{array}$ & 3 & 77 & $\left(\mathrm{CH}_{3}\right)_{2} \dot{\mathrm{C}}_{\alpha} \mathrm{C}_{6} \mathrm{H}_{5}$ & $\begin{array}{l}a_{\mathrm{CH} 3}=15.0 \\
a_{\text {ring }}=5.0(3 \mathrm{H})\end{array}$ \\
\hline $\begin{array}{l}\beta \text {-methyl- } \\
\text { styrene }\end{array}$ & 3 & 77 & $\mathrm{CH}_{3} \mathrm{C}_{\beta} \mathrm{H}_{2} \dot{\mathrm{C}}_{\alpha} \mathrm{HC}_{6} \mathrm{H}_{5}$ & $\begin{array}{l}a_{\alpha}=16.5 \\
a_{\beta 1}=31.7, a_{\beta 2}=15.6 \\
a_{\text {ring }}=4.0(3 \mathrm{H})\end{array}$ \\
\hline $\begin{array}{l}\text { Methyl- } \\
\text { methacrylate }\end{array}$ & 3 & 77 & $\left(\mathrm{CH}_{3}\right)_{2} \dot{\mathrm{C}}_{\alpha} \mathrm{COOCH}_{3}(\mathrm{R})$ & \begin{tabular}{l}
$a_{\mathrm{CH} 3}=22.0$ \\
\hline $\begin{array}{l}\text { Methyl- } \\
\text { methacrylate }\end{array}$
\end{tabular} \\
\hline
\end{tabular}


TABLE 2. Calculated isotropic hyperfine splitting constants $(\mathrm{G})$ of the $\mathrm{H}$ atom addition radical of styrene adsorbed on the $8 \mathrm{~T}$ silica model cluster.

\begin{tabular}{|c|c|c|c|c|}
\hline & \multicolumn{2}{|c|}{ M05-2X } & \multicolumn{2}{|c|}{ B3LYP } \\
\hline & $6-31+G^{*}$ & EPR-III & $6-31+G^{*}$ & EPR-III \\
\hline $\mathbf{H}_{\alpha}$ & -18.40 & -12.50 & -18.04 & -15.49 \\
\hline $\mathbf{H}_{\beta 1}$ & 15.62 & 14.86 & 16.52 & 17.07 \\
\hline $\mathrm{H}_{82}$ & 3.51 & 2.98 & 3.61 & 3.47 \\
\hline $\mathbf{H}_{83}$ & 33.06 & 31.82 & 34.55 & 36.08 \\
\hline $\mathrm{H}_{1}$ & -5.30 & -3.58 & -4.94 & -4.13 \\
\hline $\mathrm{H}_{2}$ & 2.31 & 1.01 & 1.88 & 1.16 \\
\hline $\mathrm{H}_{3}$ & -5.72 & -4.16 & -5.77 & -5.12 \\
\hline $\mathbf{H}_{4}$ & 2.33 & 1.02 & 1.90 & 1.17 \\
\hline $\mathrm{H}_{5}$ & -5.39 & -3.60 & -5.21 & -4.35 \\
\hline
\end{tabular}


TABLE 3. Calculated isotropic hyperfine splitting constants $(\mathrm{G})$ of the the $H$ atom addition radical of DPE adsorbed on the $8 \mathrm{~T}$ silica model cluster.

\begin{tabular}{|l|c|c|c|c|}
\hline & \multicolumn{2}{|c|}{ M05-2X } & \multicolumn{2}{c|}{ B3LYP } \\
\hline & $\mathbf{6 - 3 1 + G ^ { * }}$ & EPR-III & $\mathbf{6 - 3 1 + G}^{*}$ & EPR-III \\
\hline $\mathbf{H}_{\boldsymbol{B} \mathbf{1}}$ & 28.14 & 29.94 & 29.07 & 30.40 \\
\hline $\mathbf{H}_{\mathbf{B} \mathbf{2}}$ & 4.23 & 1.72 & 2.25 & 2.11 \\
\hline $\mathbf{H}_{\boldsymbol{B} \mathbf{3}}$ & 17.38 & 14.58 & 15.44 & 16.00 \\
\hline $\mathbf{H}_{\mathbf{1}} \mathbf{a} / \mathbf{b}$ & $-1.73 /-4.08$ & $-2.22 /-2.88$ & $-2.88 /-3.80$ & $-2.37 /-3.12$ \\
\hline $\mathbf{H}_{\mathbf{2}} \mathbf{a} / \mathbf{b}$ & $2.29 / 1.91$ & $0.93 / 1.04$ & $1.52 / 1.78$ & $1.10 / 1.18$ \\
\hline $\mathbf{H}_{\mathbf{3}} \mathbf{a} / \mathbf{b}$ & $-2.97 /-4.18$ & $-2.11 /-3.01$ & $-3.12 /-4.31$ & $-2.67 /-3.72$ \\
\hline $\mathbf{H}_{\mathbf{4}} \mathbf{a} / \mathbf{b}$ & $1.47 / 2.73$ & $0.84 / 0.92$ & $1.42 / 1.65$ & $0.98 / 1.03$ \\
\hline $\mathbf{H}_{\mathbf{5}} \mathbf{a} / \mathbf{b}$ & $-3.14 /-4.23$ & $-2.14 /-2.87$ & $-2.96 /-2.26$ & $-2.41 /-3.40$ \\
\hline
\end{tabular}


TABLE 4. Calculated hyperfine splitting constants $(\mathrm{G})$ of of the $\mathrm{H}$ atom addition radicals of $\alpha$ methyl styrene (AMST) and $\beta$-methyl styrene (BMST) adsorbed on the 8T silica model cluster.

\begin{tabular}{|c|c|c|c|c|c|c|c|c|c|}
\hline & \multicolumn{4}{|c|}{ AMST } & & \multicolumn{4}{|c|}{ BMST } \\
\hline & \multicolumn{2}{|c|}{ M05-2X } & \multicolumn{2}{|c|}{ B3LYP } & & \multicolumn{2}{|c|}{ M05-2X } & \multicolumn{2}{|c|}{ B3LYP } \\
\hline & $6-31+G *$ & EPR-III & $6-31+G^{*}$ & EPR-III & & $6-31+G^{*}$ & EPR-III & $6-31+G^{*}$ & EPR-III \\
\hline $\mathbf{H}_{\beta 1}$ & 19.25 & 18.41 & 20.33 & 20.87 & $\mathbf{H}_{\alpha}$ & -17.83 & -12.06 & -17.96 & -15.21 \\
\hline $\mathrm{H}_{32}$ & 1.45 & 1.10 & 1.70 & 1.40 & $\mathbf{H}_{\beta 1}$ & -7.99 & 29.03 & 31.69 & 33.04 \\
\hline $\mathbf{H}_{\beta 3}$ & 28.78 & 27.75 & 30.27 & 31.38 & $\mathbf{H}_{\beta 2}$ & 14.74 & 14.10 & 15.84 & 16.38 \\
\hline $\mathbf{H}_{\beta 4}$ & 23.65 & 22.75 & 25.02 & 25.86 & $\mathbf{H}_{\gamma 1}$ & -0.34 & -0.24 & -0.33 & -0.28 \\
\hline $\mathbf{H}_{35}$ & 0.58 & 0.25 & 0.77 & 0.43 & $\mathbf{H}_{\gamma_{2}}$ & -0.36 & -0.22 & -0.35 & -0.29 \\
\hline $\mathbf{H}_{\beta 6}$ & 25.6 & 24.61 & 26.88 & 27.77 & $\mathbf{H}_{\gamma 3}$ & -034 & -0.28 & -0.42 & -0.38 \\
\hline $\mathrm{H}_{1}$ & -4.94 & -3.27 & -4.97 & -4.02 & $\mathbf{H}_{1}$ & -5.32 & -3.64 & -5.36 & -4.37 \\
\hline $\mathrm{H}_{2}$ & 2.11 & 0.94 & 1.96 & 1.10 & $\mathbf{H}_{2}$ & 2.14 & 1.02 & 2.06 & 1.18 \\
\hline $\mathrm{H}_{3}$ & -5.22 & -3.82 & -5.37 & -4.69 & $\mathbf{H}_{3}$ & -5.80 & -4.25 & -5.96 & -5.21 \\
\hline $\mathrm{H}_{4}$ & 2.11 & 0.95 & 1.97 & 1.10 & $\mathrm{H}_{4}$ & 2.12 & 1.02 & 2.04 & 1.18 \\
\hline $\mathbf{H}_{5}$ & -4.90 & -3.24 & -4.93 & -3.97 & $\mathrm{H}_{5}$ & -5.21 & -3.59 & -5.08 & -4.13 \\
\hline
\end{tabular}


TABLE 5. Calculated isotropic hyperfine splitting constants $(\mathrm{G})$ of the of the $\mathrm{H}$ atom addition radical of methyl methacrylate adsorbed on the $8 \mathrm{~T}$ silica model cluster.

\begin{tabular}{|c|c|c|c|c|}
\hline & \multicolumn{2}{|c|}{ M05-2X } & \multicolumn{2}{|c|}{ B3LYP } \\
\hline & $6-31+G^{*}$ & EPR-III & $6-31+G^{*}$ & EPR-III \\
\hline $\mathbf{H}_{\beta 1}$ & 15.58 & 15.33 & 16.48 & 17.45 \\
\hline $\mathbf{H}_{\beta 2}$ & 35.90 & 35.86 & 38.14 & 40.71 \\
\hline $\mathbf{H}_{\beta 3}$ & 4.25 & 4.09 & 4.45 & 4.60 \\
\hline $\mathbf{H}_{\beta 4}$ & 32.78 & 32.56 & 34.82 & 37.08 \\
\hline $\mathbf{H}_{35}$ & 20.39 & 20.12 & 21.66 & 22.99 \\
\hline $\mathbf{H}_{86}$ & 2.10 & 1.98 & 2.12 & 2.11 \\
\hline
\end{tabular}


TABLE 6. Calculated hyperfine splitting constants (G) of the PMMA radical $\mathrm{RC}_{\beta} \mathrm{H}_{2} \dot{\mathrm{C}}_{\alpha}\left(\mathrm{CH}_{3}\right) \mathrm{COOCH}_{3}, \mathrm{R}=\left(\mathrm{CH}_{3}\right)_{2} \dot{\mathrm{C}}_{\alpha} \mathrm{COOCH}_{3}$.

\begin{tabular}{|c|c|c|c|c|}
\hline & \multicolumn{2}{|c|}{ M05-2X } & \multicolumn{2}{|c|}{ B3LYP } \\
\hline & $6-31+G^{*}$ & EPR-III & $6-31+G^{*}$ & EPR-III \\
\hline$a_{\mathrm{CH} 3(1)}$ & 10.62 & 10.48 & 11.40 & 12.12 \\
\hline$a_{\mathrm{CH3}(2)}$ & 37.97 & 37.94 & 40.58 & 43.50 \\
\hline$a_{\mathrm{CH3}(3)}$ & 8.62 & 8.53 & 9.32 & 9.93 \\
\hline$a_{\mathrm{CH3}(\mathrm{av})}$ & 19.07 & 18.98 & 20.43 & 21.85 \\
\hline$a_{\beta 1}$ & 16.60 & 16.54 & 18.24 & 19.42 \\
\hline$a_{\beta 2}$ & 2.74 & 2.59 & 3.07 & 3.14 \\
\hline
\end{tabular}




\section{Figure Captions}

FIGURE 1. (a) experimental EPR spectrum from a $\gamma$-irradiated sample containing $5 \%$ styrene adsorbed on silica gel $\gamma$-irradiated and recorded at $77 \mathrm{~K}$, (b-d) simulated spectra for the hydrogen atom addition radical $\mathrm{CH}_{3} \dot{\mathrm{C}}_{\alpha} \mathrm{HC}_{6} \mathrm{H}_{5}$, with $a_{\mathrm{CH} 3}=16.5,15.5$ and $14.5 \mathrm{G}$, respectively.

FIGURE 2. (a) Experimental EPR spectrum (solid line) from a sample containing (a) $5 \%$ of 1,1-diphenyl ethylene (DPE), adsorbed on silica gel $\gamma$-irradiated and recorded at $77 \mathrm{~K}$, fitted spectrum (dotted line) by superposition of (b) and (c), (b) simulated spectrum due to DPE Haddition radical, $\left(\mathrm{C}_{6} \mathrm{H}_{5}\right)_{2} \dot{\mathrm{C} C H} \mathrm{CH}_{3}$, with $a_{\mathrm{CH} 3}=16.0 \mathrm{G}$, (c) synthetic spectrum of another species assumed in the simulation of (a).

FIGURE 3. EPR spectra from samples $\gamma$-irradiated and recorded at $77 \mathrm{~K}$ containing $3 \%$ MMA adsorbed (a) on ordinary (b) on partly deuterated silica gel. The difference spectrum (b)-(a) was attributed to the radical $\mathrm{CDH}_{2} \dot{\mathrm{C}}\left(\mathrm{CH}_{3}\right) \mathrm{COOCH}_{3}$ obtained by D atom addition to MMA. Weak lines attributed to unreacted D are marked by arrows.

FIGURE 4. EPR spectra of a sample $\gamma$-irradiated at $77 \mathrm{~K}$ containing $3 \%$ MMA adsorbed on silica gel, recorded (a) at $77 \mathrm{~K},(\mathrm{~b})$ at $123 \mathrm{~K}$

FIGURE 5. (a) Experimental EPR spectrum of a sample $\gamma$-irradiated at $77 \mathrm{~K}$ containing $3 \%$ MMA adsorbed on silica gel, recorded at $123 \mathrm{~K}$, (b) simulated spectrum with $a_{\mathrm{CH} 3}=22.2 \mathrm{G}$, $a_{\beta 1}=14.7 \mathrm{G}, a_{\beta 2}=7.5 \mathrm{G}$ at an exchange rate of $32 \mathrm{MHz}$ for the $\beta$-protons of the $\mathrm{CH}_{2}$ group in the radical $\mathrm{RC}_{\beta} \mathrm{H}_{2} \dot{\mathrm{C}}_{\alpha}\left(\mathrm{CH}_{3}\right) \mathrm{COOCH}_{3}, \mathrm{R}=\left(\mathrm{CH}_{3}\right)_{2} \dot{\mathrm{C}}_{\alpha} \mathrm{COOCH}_{3}$, (c) simulated rigid limit spectrum.

FIGURE 6. Optimized structure of $8 \mathrm{~T}$ cluster as a model of $\mathrm{SiO}_{2}$

FIGURE 7. Optimized styrene radical structure adsorbed on the 8T silica model cluster. 
FIGURE 8. Optimized structure of DPE radical adsorbed on the $8 \mathrm{~T}$ silica model cluster.

FIGURE 9. Optimized structures of AMST (a) and BMST (b) radicals adsorbed on the $8 \mathrm{~T}$ silica model cluster.

FIGURE 10. Optimized structure of the MMA radical adsorbed on the 8T silica model cluster.

FIGURE 11. Molecular structures and energy profile for the reaction $\mathrm{R}+\mathrm{CH}_{2}=\mathrm{C}\left(\mathrm{CH}_{3}\right) \mathrm{COOCH}_{3}$ $\rightarrow \mathrm{RC}_{\beta} \mathrm{H}_{2} \dot{\mathrm{C}}_{\alpha}\left(\mathrm{CH}_{3}\right) \mathrm{COOCH}_{3}, \mathrm{R}=\left(\mathrm{CH}_{3}\right)_{2} \dot{\mathrm{CCOOCH}}_{3}$, at the M05-2X/6-311+G(2df,2p)//M052X/6-31G(d) level. (ZPE corrected energies in $\mathrm{kcal} / \mathrm{mol}$ ) 


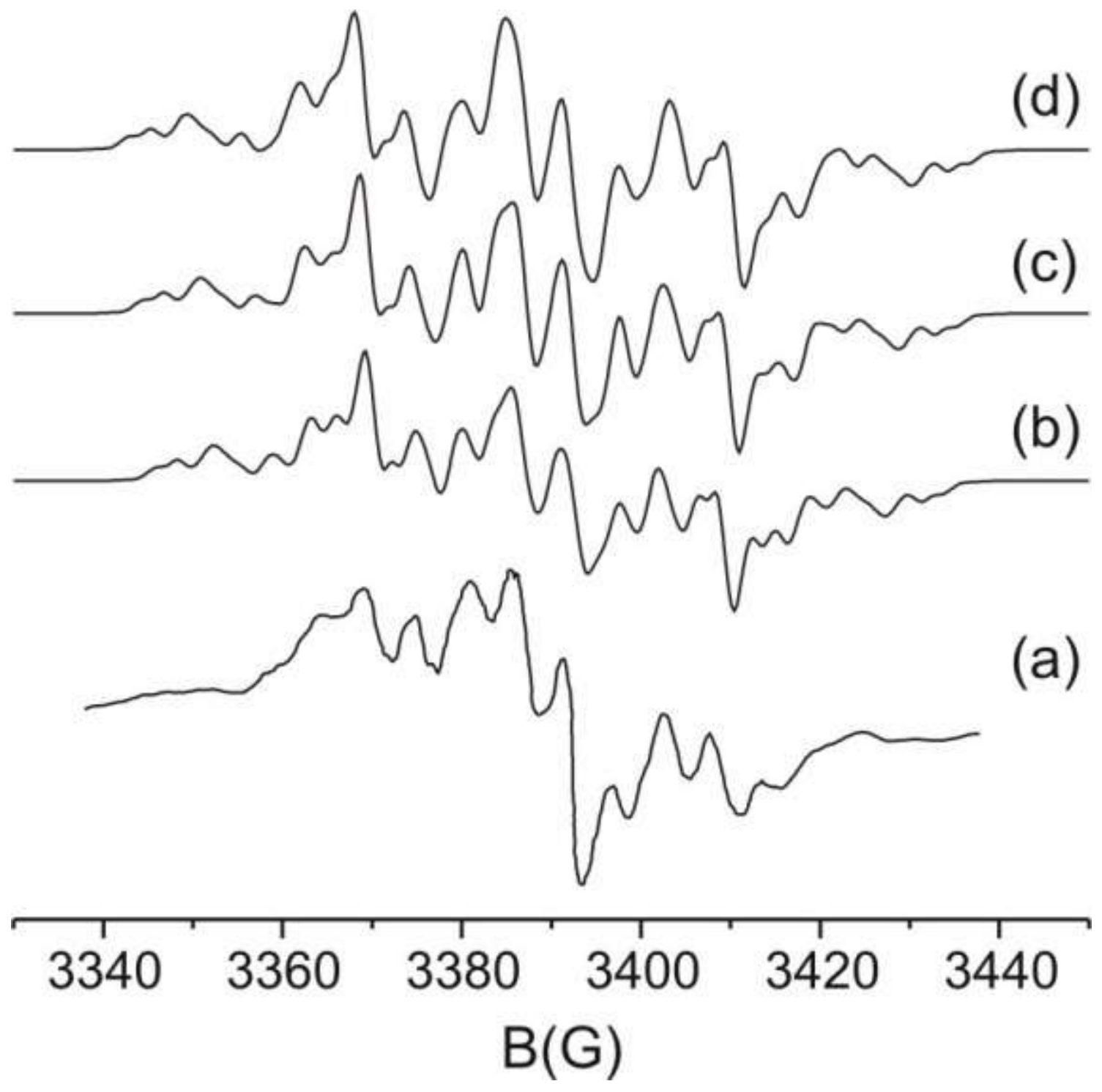

FIGURE 1. (a) experimental EPR spectrum from a $\gamma$-irradiated sample containing $5 \%$ styrene adsorbed on silica gel $\gamma$-irradiated and recorded at $77 \mathrm{~K}$, (b-d) simulated spectra for the hydrogen atom addition radical $\mathrm{CH}_{3} \dot{\mathrm{C}}_{\alpha} \mathrm{HC}_{6} \mathrm{H}_{5}$, with $a_{\mathrm{CH} 3}=16.5,15.5$ and $14.5 \mathrm{G}$, respectively. 


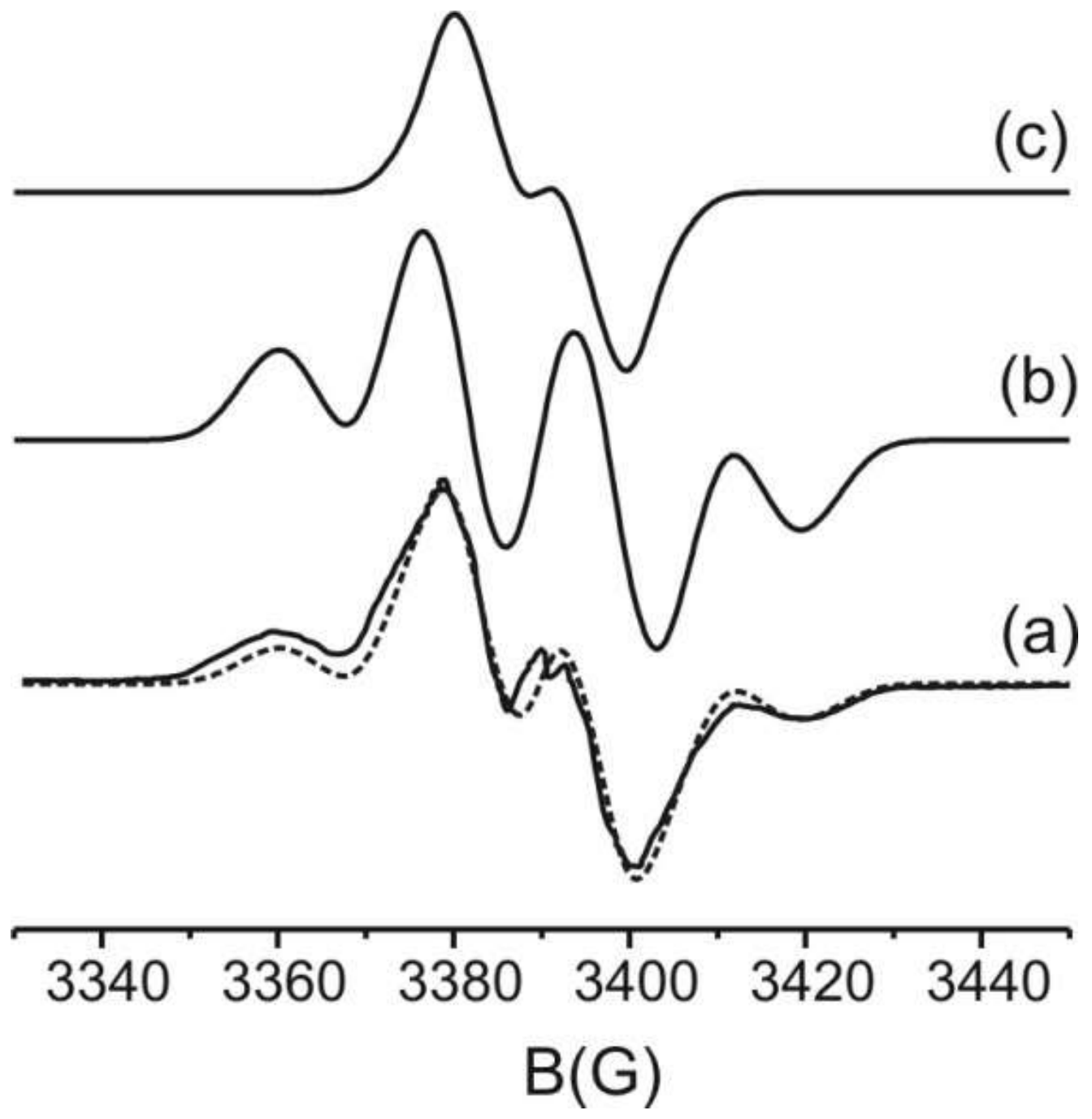

FIGURE 2. (a) Experimental EPR spectrum (solid line) from a sample containing (a) $5 \%$ of 1,1-diphenyl ethylene (DPE), adsorbed on silica gel $\gamma$-irradiated and recorded at $77 \mathrm{~K}$, fitted spectrum (dotted line) by superposition of (b) and (c), (b) simulated spectrum due to DPE Haddition radical, $\left(\mathrm{C}_{6} \mathrm{H}_{5}\right)_{2} \dot{\mathrm{C}} \mathrm{CH}_{3}$, with $a_{\mathrm{CH} 3}=16.0 \mathrm{G}$, (c) synthetic spectrum of another species assumed in the simulation of (a). 


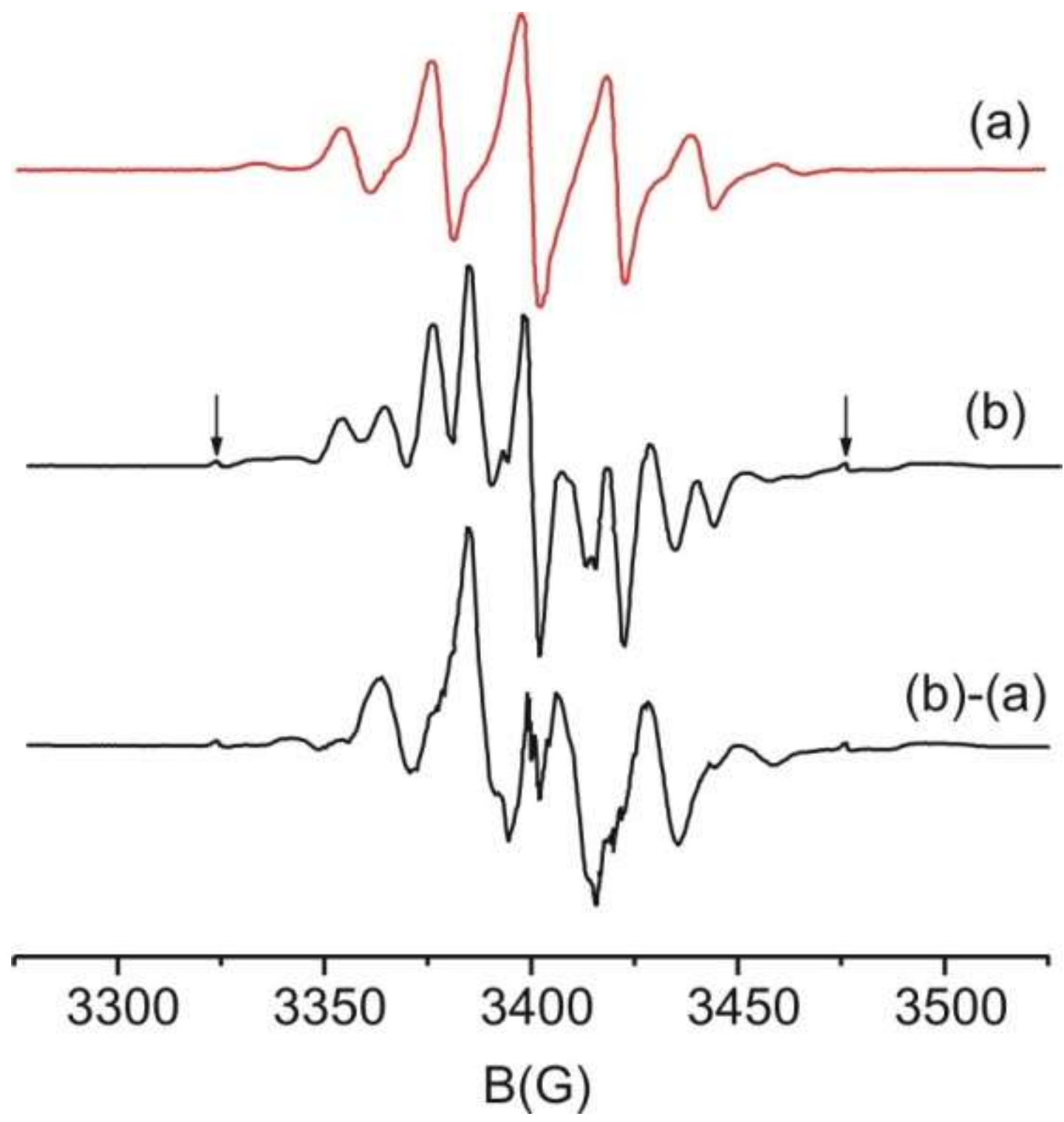

FIGURE 3. EPR spectra from samples $\gamma$-irradiated and recorded at $77 \mathrm{~K}$ containing $3 \%$ MMA adsorbed (a) on ordinary (b) on partly deuterated silica gel. The difference spectrum (b)-(a) was attributed to the radical $\mathrm{CDH}_{2} \dot{\mathrm{C}}\left(\mathrm{CH}_{3}\right) \mathrm{COOCH}_{3}$ obtained by D atom addition to MMA. Weak lines attributed to unreacted $\mathrm{D}$ are marked by arrows. 


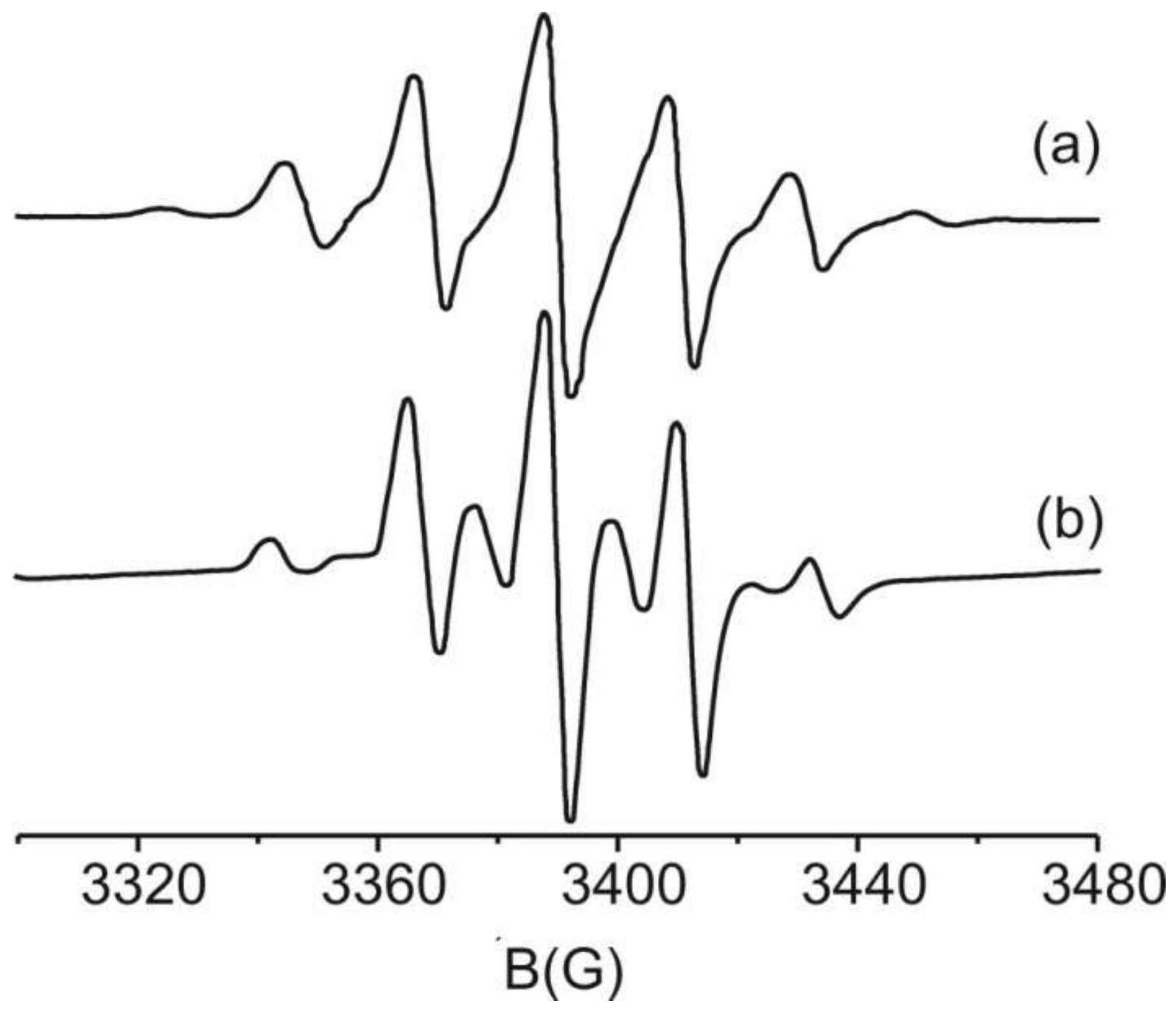

FIGURE 4. EPR spectra of a sample $\gamma$-irradiated at $77 \mathrm{~K}$ containing $3 \%$ MMA adsorbed on silica gel, recorded (a) at $77 \mathrm{~K}$, (b) at $123 \mathrm{~K}$ 


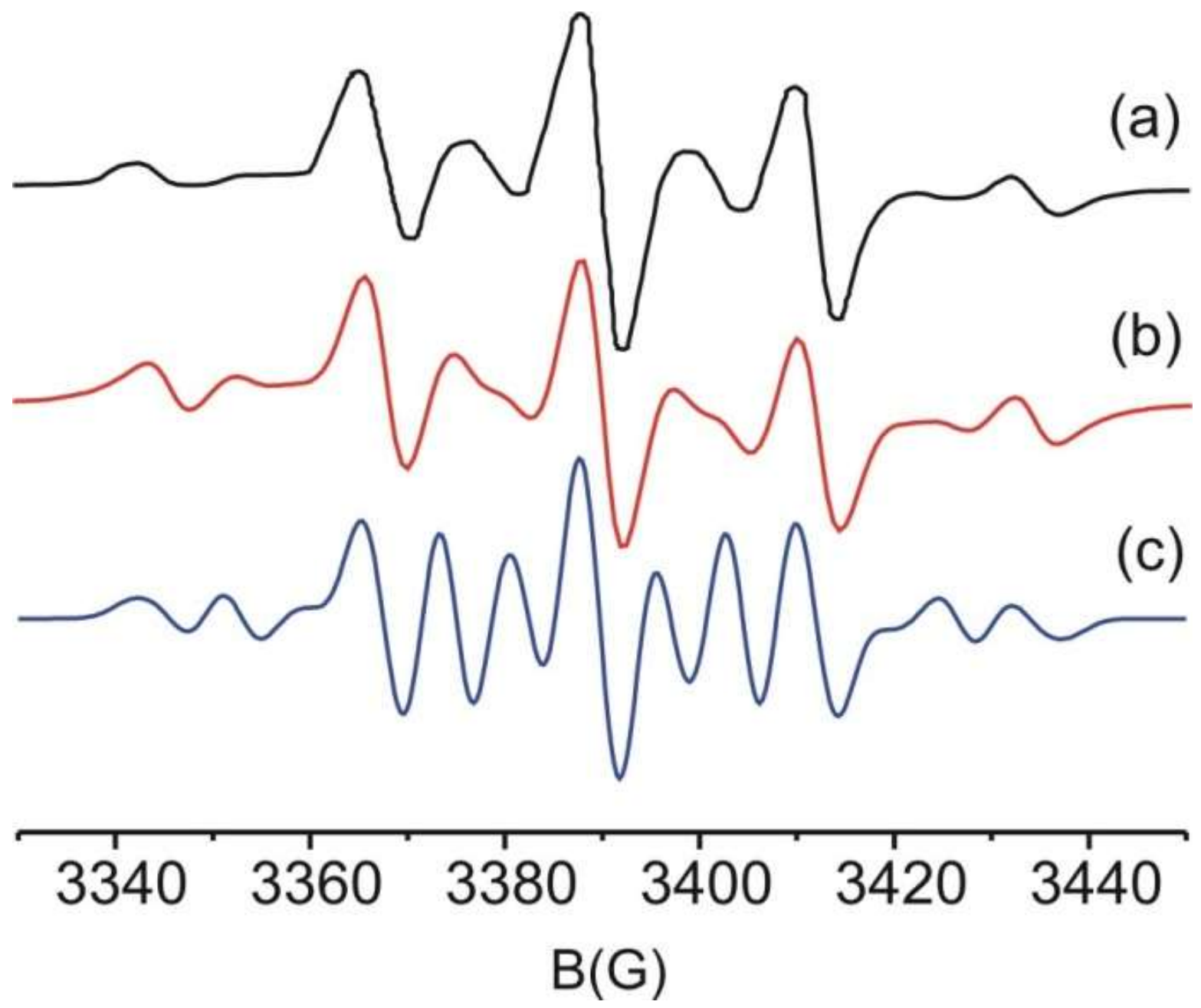

FIGURE 5. (a) Experimental EPR spectrum of a sample $\gamma$-irradiated at $77 \mathrm{~K}$ containing $3 \%$ MMA adsorbed on silica gel, recorded at $123 \mathrm{~K}$, (b) simulated spectrum with $a_{\mathrm{CH} 3}=22.2 \mathrm{G}, a_{\beta 1}$ $=14.7 \mathrm{G}, a_{\beta 2}=7.5 \mathrm{G}$ at an exchange rate of $32 \mathrm{MHz}$ for the $\beta$-protons of the $\mathrm{CH}_{2}$ group in the radical $\mathrm{RC}_{\beta} \mathrm{H}_{2} \dot{\mathrm{C}}_{\alpha}\left(\mathrm{CH}_{3}\right) \mathrm{COOCH}_{3}, \mathrm{R}=\left(\mathrm{CH}_{3}\right)_{2} \dot{\mathrm{C}}_{\alpha} \mathrm{COOCH}_{3}$, (c) simulated rigid limit spectrum. 


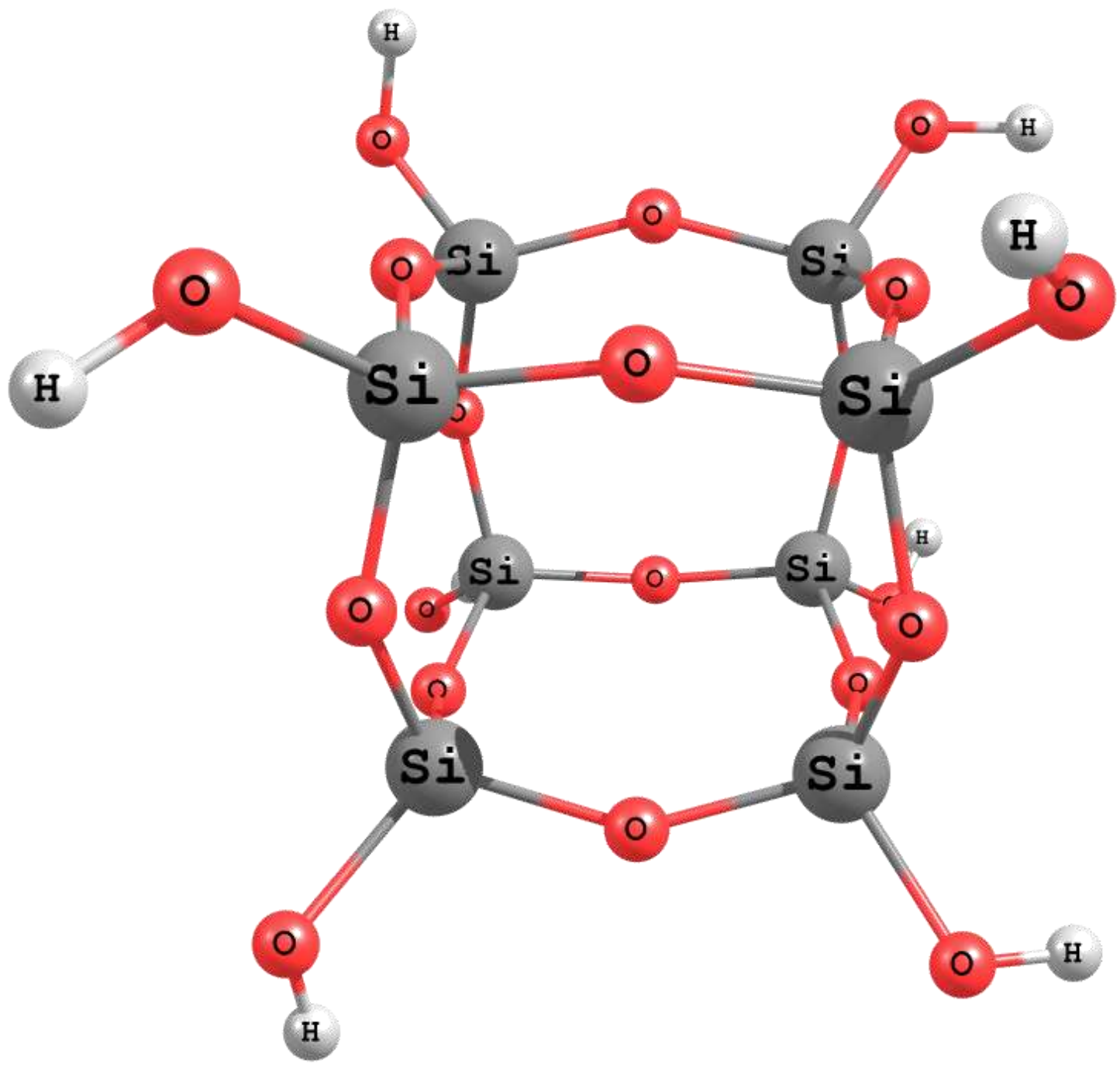


FIGURE 6. Optimized structure of $8 \mathrm{~T}$ cluster as a model of $\mathrm{SiO}_{2}$

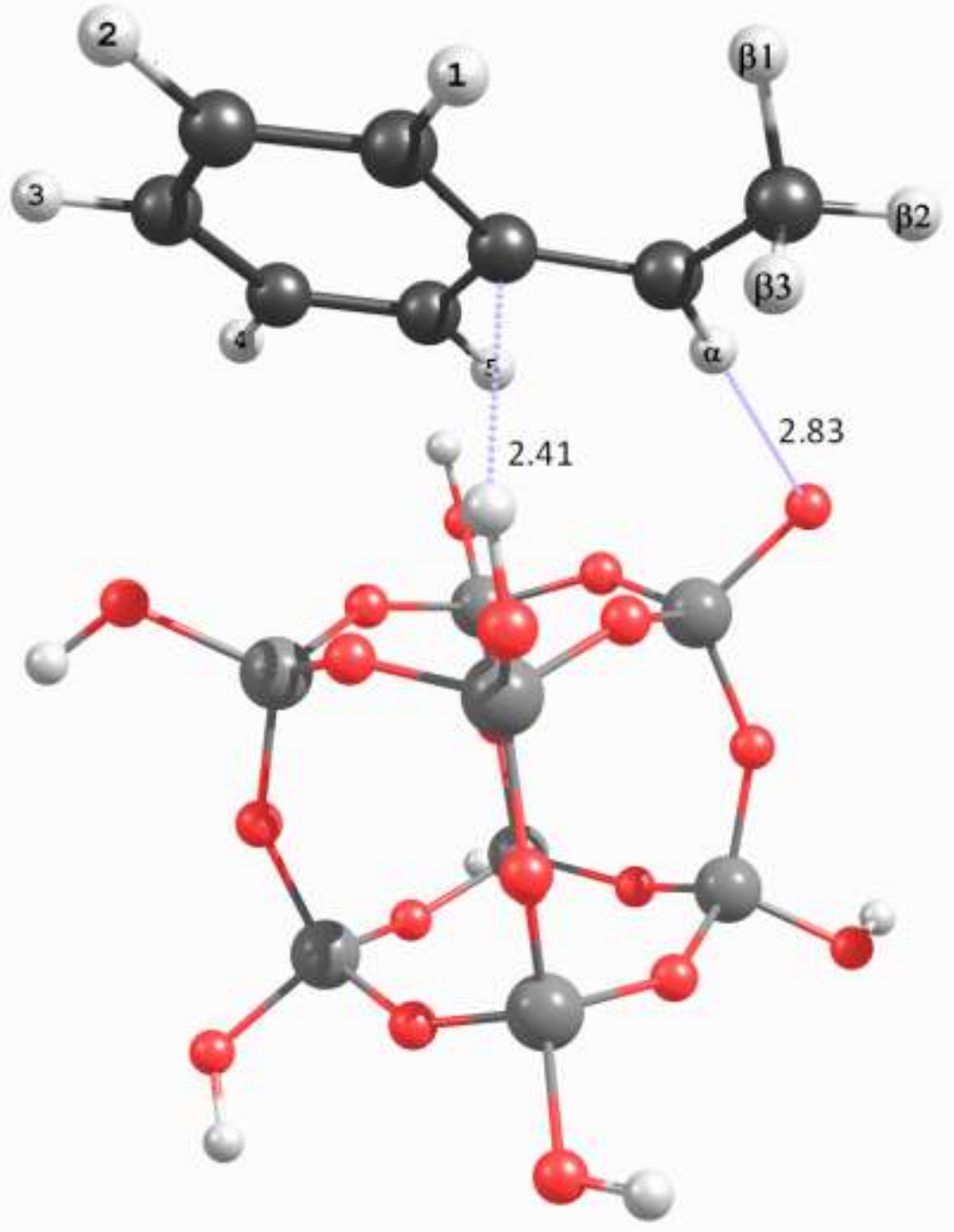

(B)

(2)

(C)

Si

FIGURE 7. Optimized styrene radical structure adsorbed on the 8T silica model cluster. 


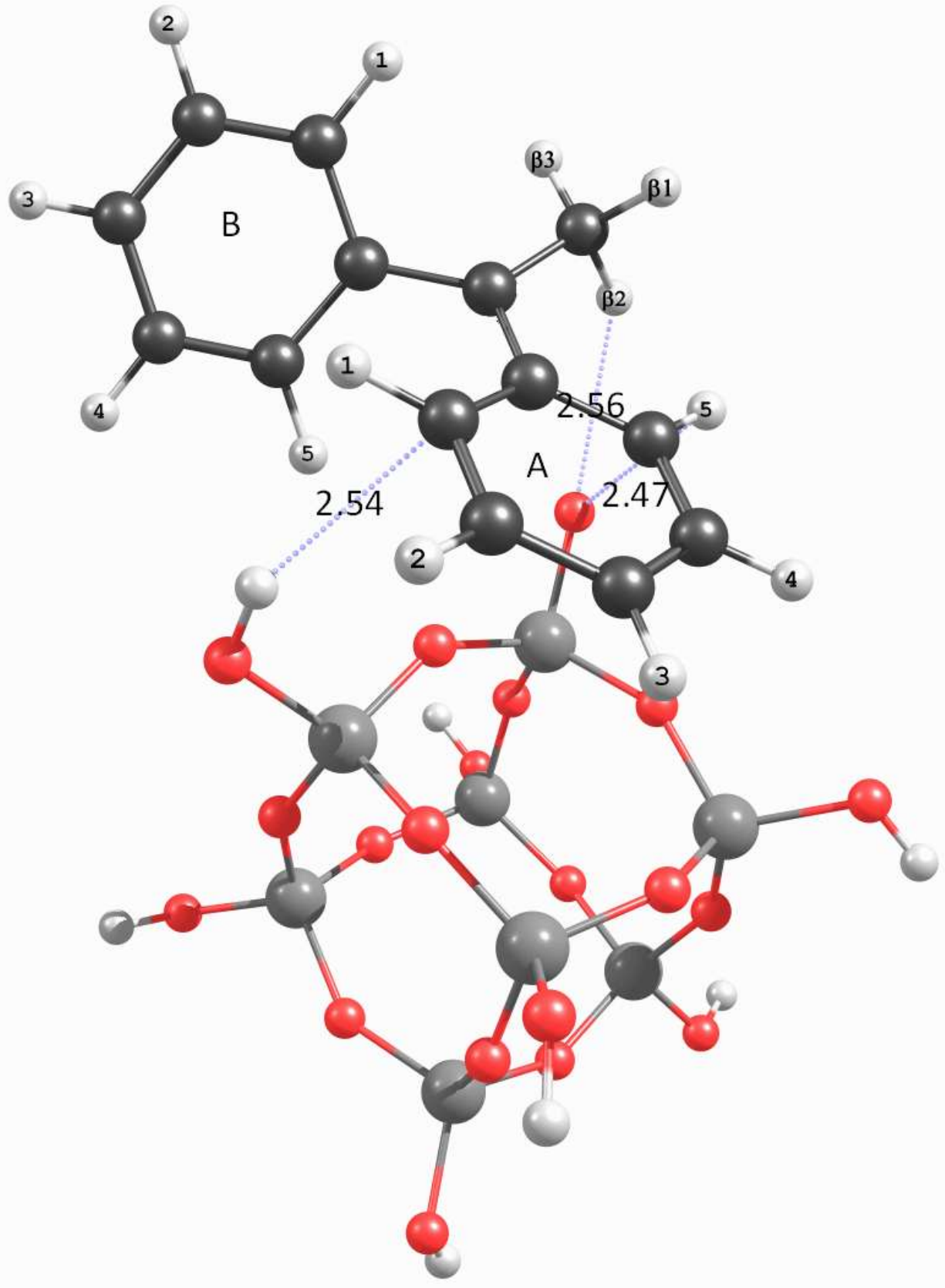

FIGURE 8. Optimized structure of DPE radical adsorbed on the 8T silica model cluster. 
(a)

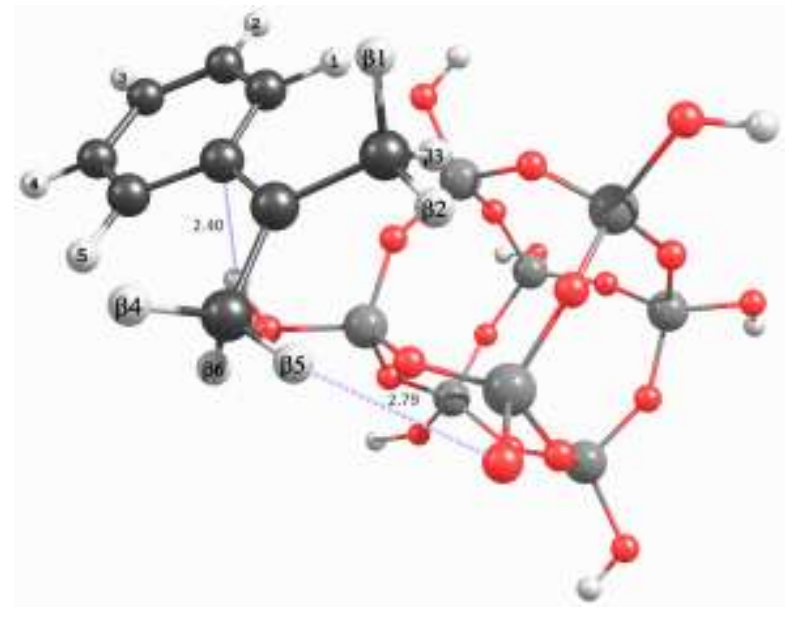

(b)

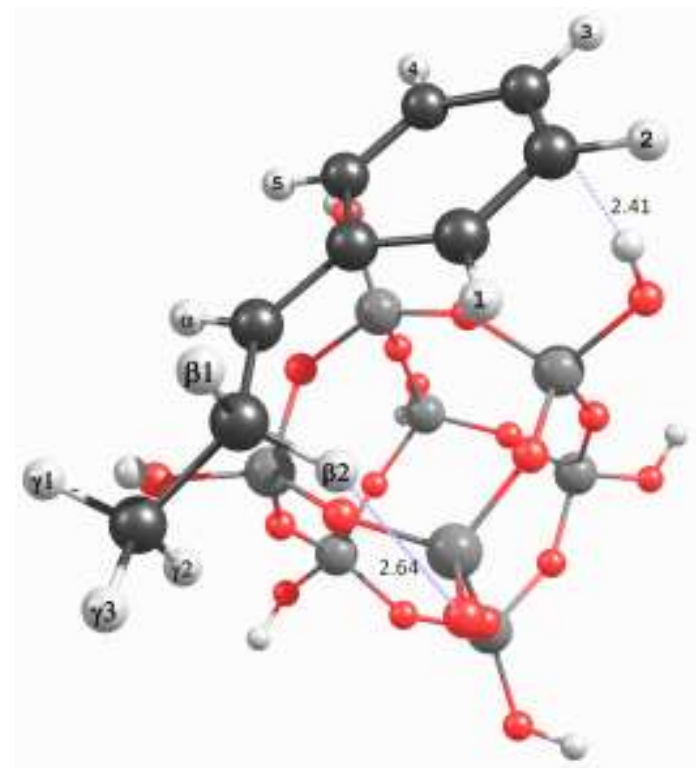

FIGURE 9. Optimized structures of AMST (a) and BMST (b) radicals adsorbed on $\mathrm{SiO}_{2}$ silica model cluster. 


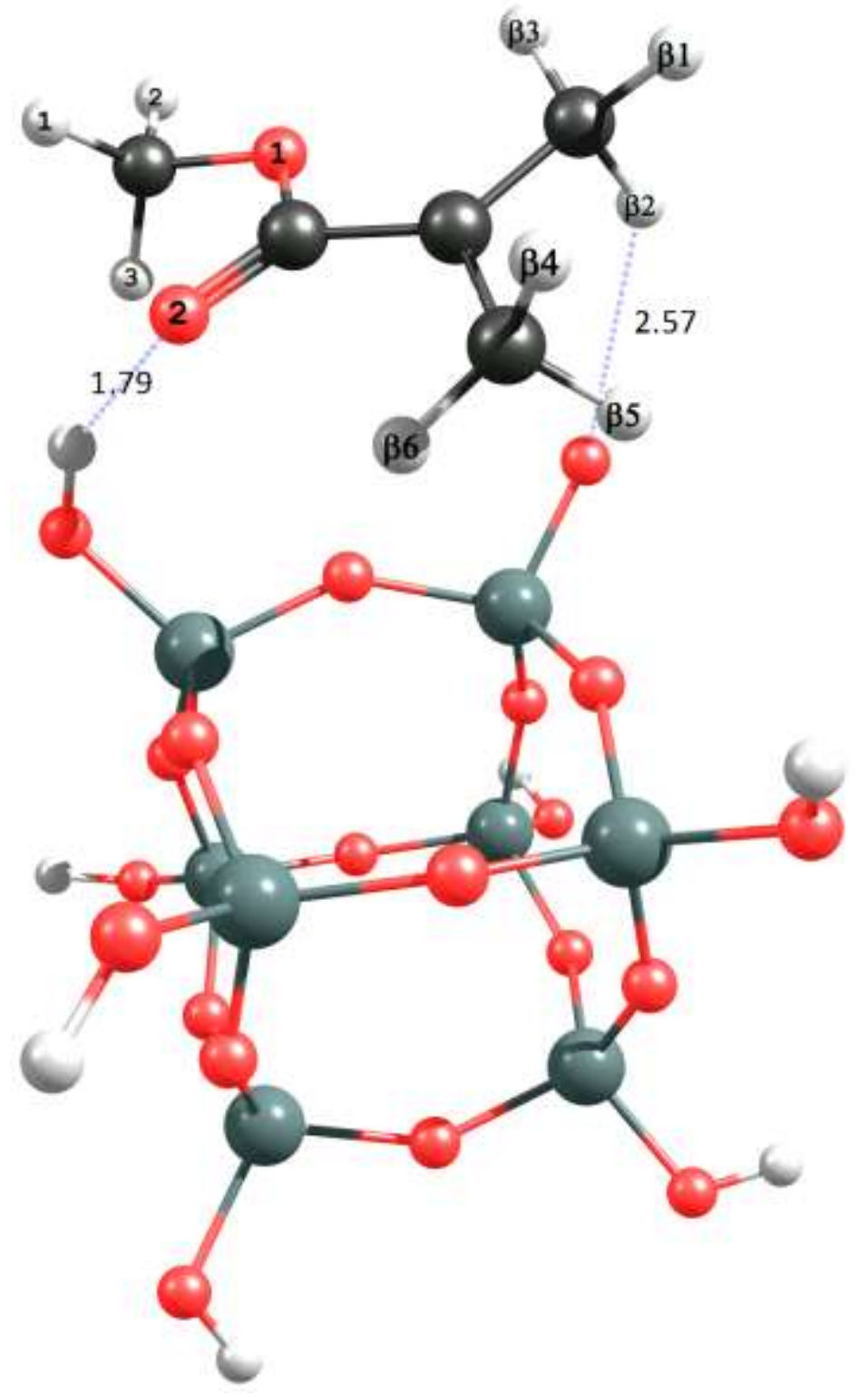

FIGURE 10. Optimized structure of the MMA radical adsorbed on the 8T silica model cluster. 

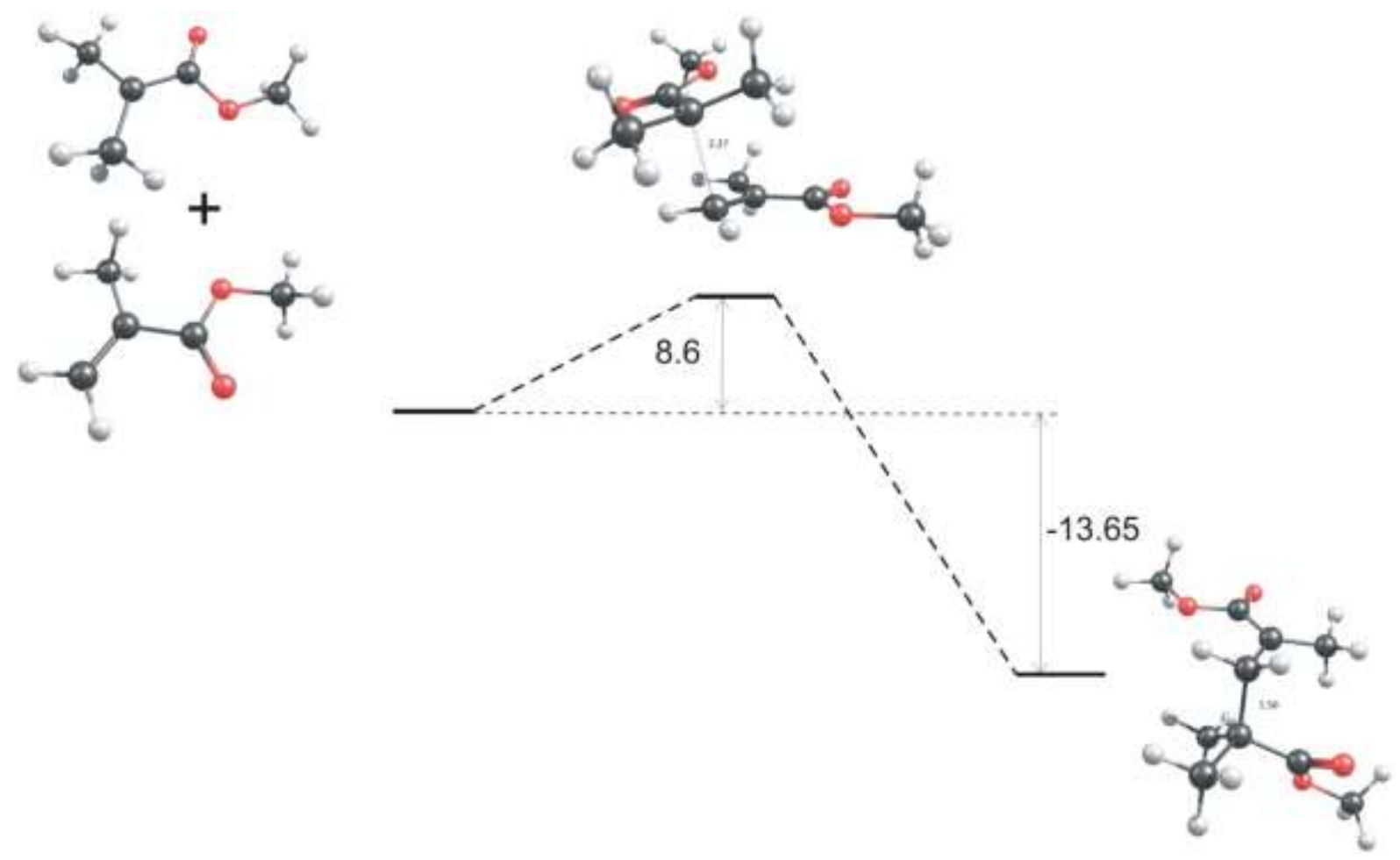

FIGURE 11. Molecular structures and energy profile for the reaction $\mathrm{R}+\mathrm{CH}_{2}=\mathrm{C}\left(\mathrm{CH}_{3}\right) \mathrm{COOCH}_{3} \rightarrow \mathrm{RC}_{\beta} \mathrm{H}_{2} \dot{\mathrm{C}}_{\alpha}\left(\mathrm{CH}_{3}\right) \mathrm{COOCH}_{3}, \mathrm{R}=\left(\mathrm{CH}_{3}\right)_{2} \dot{\mathrm{CCOOCH}}_{3}$, at the M052X/6-311+G(2df,2p)//M05-2X/6-31G(d) level. (ZPE corrected energies in $\mathrm{kcal} / \mathrm{mol}$ ) 


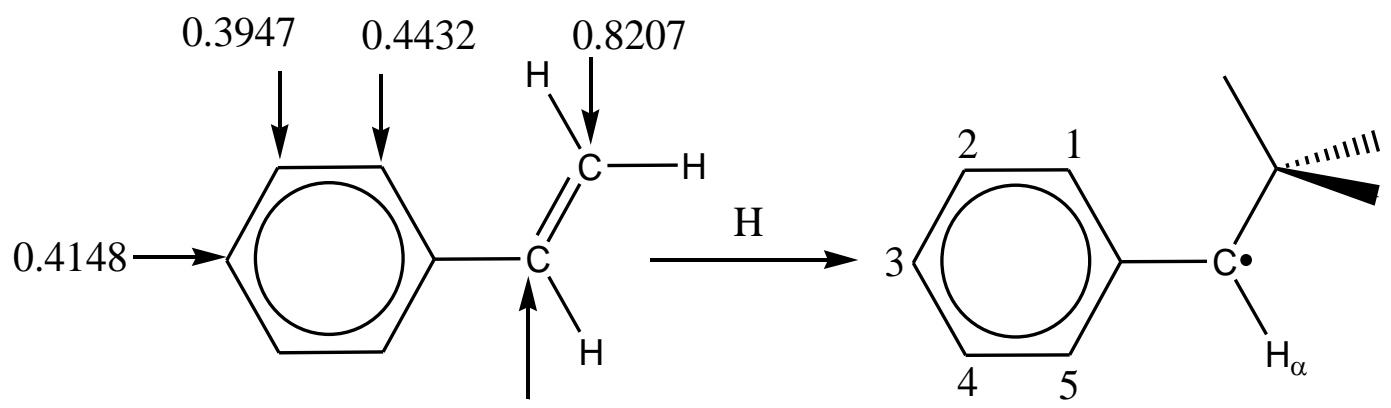

0.4148

SCHEME 1: Formation of $\mathrm{CH}_{3} \dot{\mathrm{C}}_{\alpha} \mathrm{HC}_{6} \mathrm{H}_{5}$ radical by hydrogen atom addition to styrene at the position of highest free valence index, defined by $F_{i}=\sqrt{3}-\sum_{j} P_{i j}$, [36] where $P_{i j}$ is the bond order for the $\mathrm{C}_{\mathrm{i}}-\mathrm{C}_{\mathrm{j}}$ bond in Hückel molecular orbital theory. 


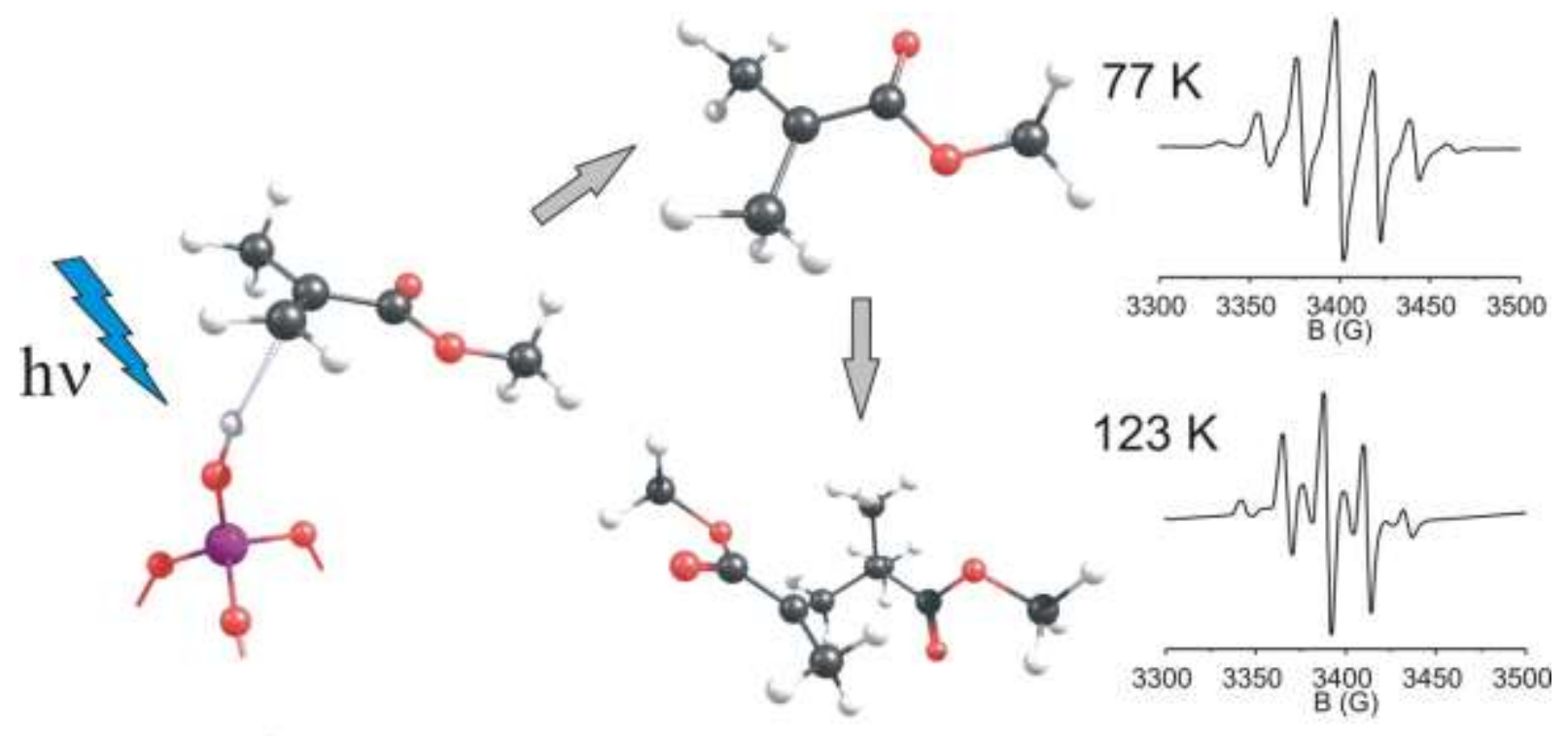

Graphical abstract: $\mathrm{H}$ atoms released by irradiation of surface silanol groups initiate radical formation in methylmethacrylate, MMA. The radical attacks an MMA molecule at increased temperature forming a propagating radical identified by EPR. 


\section{Supplementary Information}

Monomer- and Polymer radicals of Vinyl Compounds: EPR and DFT Studies of Geometric and Electronic Structures in the Adsorbed State

Anders Lund ${ }^{\mathrm{a}^{*}}$ and Marek Danilczuk ${ }^{\mathrm{b}}$

${ }^{a}$ Department of Physics, Chemistry and Biology, IFM, Linköping University, S-581 83

Linköping, Sweden

${ }^{b}$ Institute of Nuclear Chemistry and Technology, Dorodna 16, 03-195 Warsaw, Poland

Corresponding author:

Anders Lund

e-mail: alund@ifm.liu.se 


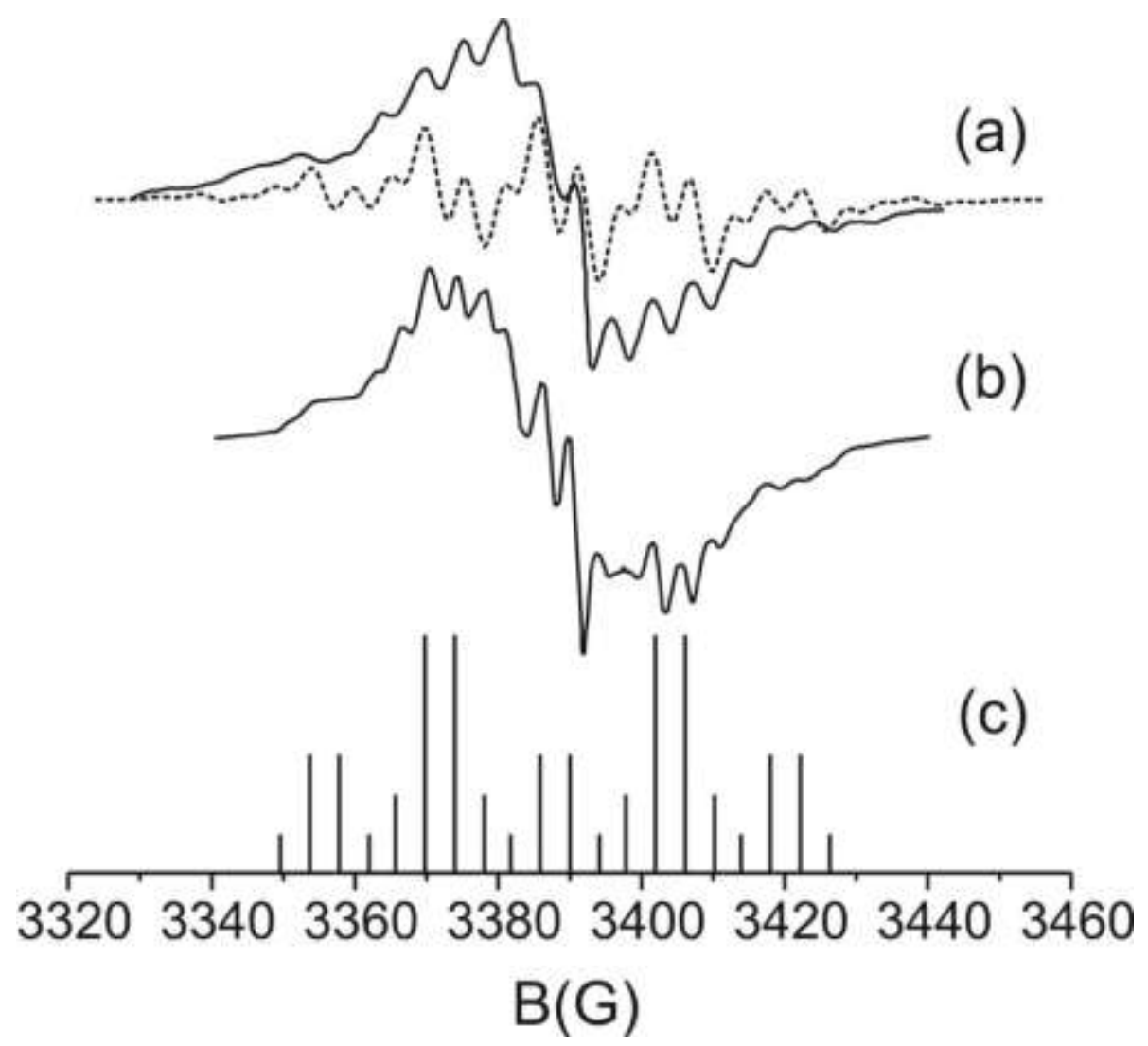

FIGURE 1S. EPR spectra from samples, $\gamma$-irradiated and recorded at $77 \mathrm{~K}$ (a) of $3 \% \alpha$ methyl styrene adsorbed on silica gel, and simulated spectrum (dotted line) with isotropic coupling constants $a_{\mathrm{CH} 3}=15.0 \mathrm{G}, a_{\text {ring }}=5.0 \mathrm{G}(3 \mathrm{H})$ for the $\left(\mathrm{CH}_{3}\right)_{2} \dot{\mathrm{CC}}_{6} \mathrm{H}_{5}$ radical, (b) of $3 \%$ $\beta$-methyl styrene, adsorbed on silica gel. (c) stickplot for the $\mathrm{CH}_{3} \mathrm{CH}_{2} \dot{\mathrm{C}}_{\alpha} \mathrm{HC}_{6} \mathrm{H}_{5}$ radical with coupling constants $a_{\alpha}=a_{\beta 1}=15.6 \mathrm{G}, a_{\beta 2}=31.2 \mathrm{G}, a_{\text {ring }}=4.0 \mathrm{G}(3 \mathrm{H})$. 


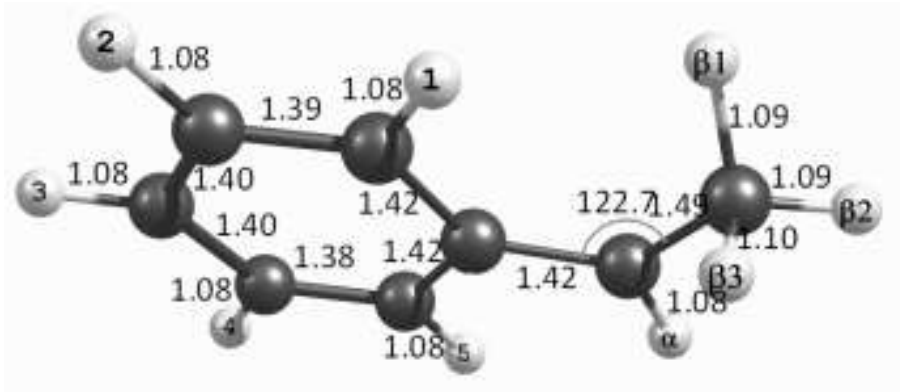

TABLE 1S. Calculated anisotropic hyperfine splitting constants of the $\mathrm{H}$ atom addition radical of styrene. The silica cluster was removed from all figures to enhance clarity.

\begin{tabular}{|c|c|c|c|c|c|}
\hline & & \multicolumn{2}{|l|}{ M05-2X } & \multicolumn{2}{|l|}{ B3LYP } \\
\hline & & 6-31+G* & EPR-III & 6-31+G* & EPR-III \\
\hline \multirow{4}{*}{$\overline{H_{\alpha}}$} & $A_{1}$ & -8.29 & -2.61 & $\begin{array}{l}-8.38 \\
\end{array}$ & $\begin{array}{l}-5.48 \\
\end{array}$ \\
\hline & $A_{2}$ & -17.31 & -12.58 & -17.25 & -15.85 \\
\hline & $A_{3}$ & -29.60 & 22.31 & -28.45 & -25.14 \\
\hline & $A_{\text {iso }}$ & -18.40 & -12.50 & -18.04 & -15.49 \\
\hline \multirow[t]{4}{*}{$\overline{H_{\beta 1}}$} & $A_{1}$ & 14.19 & 13.42 & 15.16 & 15.67 \\
\hline & $A_{2}$ & 14.50 & 13.94 & 15.53 & 16.19 \\
\hline & $A_{3}$ & 18.17 & 17.22 & 18.87 & 19.35 \\
\hline & $A_{\text {iso }}$ & 15.62 & 14.86 & 16.52 & 17.07 \\
\hline \multirow[t]{4}{*}{$\mathrm{H}_{\beta 2}$} & $A_{1}$ & 2.04 & 1.66 & 2.27 & 2.17 \\
\hline & $A_{2}$ & 2.34 & 1.84 & 2.49 & 2.37 \\
\hline & $A_{3}$ & 6.15 & 5.44 & 6.07 & 5.87 \\
\hline & $A_{\text {iso }}$ & 3.51 & 2.98 & 3.61 & 3.47 \\
\hline \multirow{4}{*}{$\mathbf{H}_{\beta 3}$} & $A_{1}$ & 31.53 & 30.32 & 33.16 & 34.71 \\
\hline & $A_{2}$ & 31.92 & 31.82 & 33.49 & 35.02 \\
\hline & $A_{3}$ & 35.73 & 34.32 & 37.00 & 38.51 \\
\hline & $A_{\text {iso }}$ & 33.06 & 31.82 & 34.55 & 36.08 \\
\hline \multirow[t]{4}{*}{$\mathrm{H}_{1}$} & $A_{1}$ & -6.86 & -5.00 & -6.46 & $\begin{array}{l}-5.63 \\
\end{array}$ \\
\hline & $A_{2}$ & -6.28 & -4.35 & -5.87 & -4.85 \\
\hline & $A_{3}$ & -2.74 & -1.39 & -2.49 & -1.90 \\
\hline & $A_{\text {iso }}$ & -5.30 & -3.58 & -4.94 & -4.13 \\
\hline \multirow[t]{4}{*}{$\mathbf{H}_{2}$} & $A_{1}$ & 1.65 & 0.23 & 1.18 & 0.36 \\
\hline & $A_{2}$ & 1.74 & 0.81 & 1.59 & 1.08 \\
\hline & $A_{3}$ & 3.54 & 1.99 & 2.87 & 2.04 \\
\hline & $A_{\text {iso }}$ & 2.31 & 1.01 & 1.88 & 1.16 \\
\hline \multirow[t]{4}{*}{$\mathbf{H}_{3}$} & $A_{1}$ & -8.97 & -7.42 & -8.95 & -8.42 \\
\hline & $A_{2}$ & -6.01 & -4.08 & -5.98 & -4.98 \\
\hline & $A_{3}$ & -2.18 & -0.98 & -2.38 & -1.97 \\
\hline & $A_{\text {iso }}$ & -5.72 & -4.16 & -5.77 & -5.12 \\
\hline \multirow[t]{4}{*}{$\mathbf{H}_{4}$} & $A_{1}$ & 1.67 & 0.24 & 1.19 & 0.37 \\
\hline & $A_{2}$ & 1.75 & 0.82 & 1.60 & 1.09 \\
\hline & $A_{3}$ & 3.57 & 2.00 & 2.91 & 2.05 \\
\hline & $A_{\text {iso }}$ & 2.33 & 1.02 & 1.90 & 1.17 \\
\hline \multirow[t]{4}{*}{$\mathbf{H}_{5}$} & $A_{1}$ & -7.16 & -5.26 & -6.92 & -6.09 \\
\hline & $A_{2}$ & -6.28 & -4.18 & -5.99 & -4.85 \\
\hline & $A_{3}$ & -2.74 & -1.36 & 2.72 & -2.11 \\
\hline & $A_{\text {iso }}$ & -5.39 & -3.60 & -5.21 & -4.35 \\
\hline
\end{tabular}




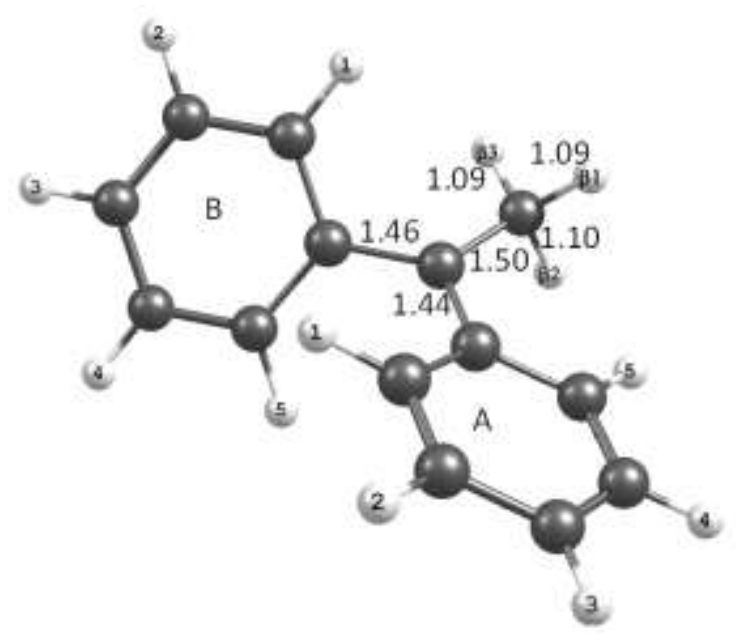

TABLE 2S. Calculated anisotropic hyperfine splitting constants $(\mathrm{G})$ of the $\mathrm{H}$ atom addition radical of 1,1-diphenylethylene.

\begin{tabular}{|c|c|c|c|c|c|}
\hline & & \multicolumn{2}{|c|}{ M05-2X } & \multicolumn{2}{|c|}{ B3LYP } \\
\hline & & $6-31+G^{*}$ & EPR-III & $6-31+G^{*}$ & EPR-III \\
\hline \multirow[t]{4}{*}{$\mathrm{H}_{\beta 1}$} & $A_{1}$ & 26.75 & 27.59 & 27.81 & 29.14 \\
\hline & $A_{2}$ & 27.07 & 26.21 & 28.06 & 29.4 \\
\hline & $A_{3}$ & 30.6 & 26.62 & 31.34 & 32.66 \\
\hline & $A_{\text {iso }}$ & 28.14 & 29.94 & 29.07 & 30.40 \\
\hline \multirow{4}{*}{$\mathrm{H}_{\beta 2}$} & $A_{1}$ & 2.00 & 0.62 & 1.19 & 1.05 \\
\hline & $A_{2}$ & 0.86 & 0.68 & 1.22 & 1.13 \\
\hline & $A_{3}$ & 0.91 & 3.86 & 4.34 & 4.15 \\
\hline & $A_{\text {iso }}$ & 4.23 & 1.72 & 2.25 & 2.11 \\
\hline \multirow[t]{4}{*}{$\mathrm{H}_{\beta 3}$} & $A_{1}$ & 15.08 & 13.23 & 14.18 & 14.69 \\
\hline & $A_{2}$ & 13.75 & 13.72 & 14.58 & 15.21 \\
\hline & $A_{3}$ & 14.11 & 16.79 & 17.56 & 18.1 \\
\hline & $A_{\text {iso }}$ & 14.38 & 14.58 & 15.44 & 16.00 \\
\hline \multirow[t]{4}{*}{$\mathrm{H}_{1}$} & $A_{1}$ & $-3.13 /-5.05$ & $-3.1 /-3.76$ & $-3.79 /-2.82$ & $-3.21 /-4.05$ \\
\hline & $A_{2}$ & $-4.07 /-4.9$ & $-2.59 /-3.56$ & $-3.34 /-4.59$ & $-2.77 /-3.77$ \\
\hline & $A_{3}$ & $-3.59 /-2.29$ & $-0.97 /-1.32$ & $-1.51 /-2.03$ & $-1.13 /-1.54$ \\
\hline & $A_{\text {iso }}$ & $-1.73 /-4.08$ & $-2.22 /-2.88$ & $-2.88 /-3.80$ & $-2.37 /-3.12$ \\
\hline \multirow[t]{4}{*}{$\mathrm{H}_{2}$} & $A_{1}$ & $1.55 / 1.37$ & $0.43 / 0.43$ & $1.06 / 1.22$ & $0.58 / 0.56$ \\
\hline & $A_{2}$ & $1.09 / 1.5$ & $0.8 / 0.86$ & $1.33 / 1.52$ & $1.03 / 1.09$ \\
\hline & $A_{3}$ & $1.27 / 2.86$ & $1.56 / 1.83$ & $2.18 / 2.6$ & $1.69 / 1.89$ \\
\hline & $A_{\text {iso }}$ & $2.29 / 1.91$ & $0.93 / 1.04$ & $1.52 / 1.78$ & $1.10 / 1.18$ \\
\hline \multirow[t]{4}{*}{$\mathrm{H}_{3}$} & $A_{1}$ & $-4.71 /-6.56$ & $-3.81 /-5.37$ & $-4.87 /-6.68$ & $-4.43 /-6.12$ \\
\hline & $A_{2}$ & $-3.16 /-4.4$ & $-2.13 /-2.99$ & $-3.29 /-4.48$ & $-2.65 /-3.64$ \\
\hline & $A_{3}$ & $-1.04 /-1.58$ & $-0.39 /-0.67$ & $-1.2 /-1.77$ & $-0.93 /-1.4$ \\
\hline & $A_{\text {iso }}$ & $-2.97 /-4.18$ & $-2.11 /-3.01$ & $-3.12 /-4.31$ & $-2.67 /-3.72$ \\
\hline \multirow[t]{4}{*}{$\mathrm{H}_{4}$} & $A_{1}$ & $1.02 / 1.79$ & $0.34 / 0.31$ & $0.95 / 1.08$ & $0.46 / 0.4$ \\
\hline & $A_{2}$ & $1.23 / 1.24$ & $0.77 / 0.76$ & $1.28 / 1.42$ & $0.97 / 0.98$ \\
\hline & $A_{3}$ & $2.16 / 1.4$ & $1.41 / 1.69$ & $2.03 / 2.45$ & $1.51 / 1.71$ \\
\hline & $A_{\text {iso }}$ & $1.47 / 2.73$ & $0.84 / 0.92$ & $1.42 / 1.65$ & $0.98 / 1.03$ \\
\hline \multirow[t]{4}{*}{$\mathrm{H}_{5}$} & $A_{1}$ & $-4.23 /-5.43$ & $-3.13 /-3.99$ & $-4.03 /-4.16$ & $-3.39 /-4.58$ \\
\hline & $A_{2}$ & $-3.68 /-4.98$ & $-2.62 /-3.43$ & $-3.5 /-5.37$ & $-2.91 /-3.88$ \\
\hline & $A_{3}$ & $-0.51 /-2.28$ & $-0.67 /-1.19$ & $-1.35 /-4.85$ & $-0.93 /-1.74$ \\
\hline & $A_{\text {iso }}$ & $-3.14 /-4.23$ & $-2.14 /-2.87$ & $-2.96 /-2.26$ & $-2.41 /-3.40$ \\
\hline
\end{tabular}


AMST

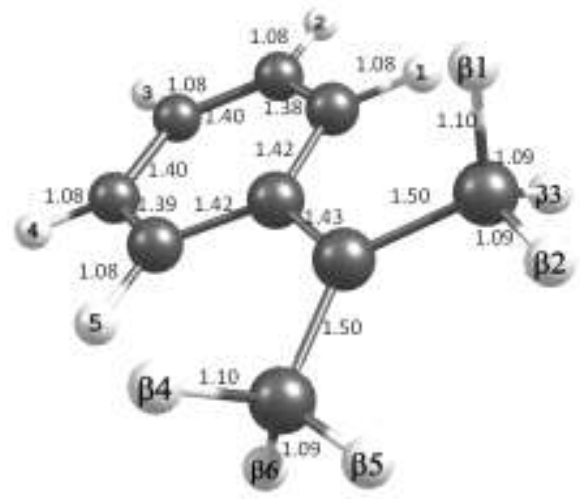

BMST

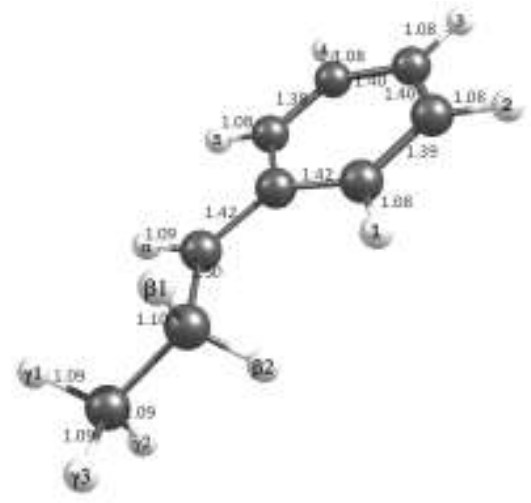

TABLE 3S. Calculated anisotropic hyperfine splitting constants $(\mathrm{G})$ of the $\mathrm{H}$ atom addition radicals of $\alpha$-methyl styrene (AMST) and $\beta$-methyl styrene (BMST).

\begin{tabular}{|c|c|c|c|c|c|c|c|c|c|c|}
\hline & & \multicolumn{4}{|c|}{ AMST } & & \multicolumn{4}{|c|}{ BMST } \\
\hline & & \multicolumn{2}{|c|}{ M05-2X } & \multicolumn{2}{|c|}{ B3LYP } & & \multicolumn{2}{|c|}{ M05-2X } & \multicolumn{2}{|c|}{ B3LYP } \\
\hline & & $6-31+G^{*}$ & EPR-III & $6-31+G^{*}$ & EPR-III & & $6-31+G^{*}$ & EPR-III & $6-31+G^{*}$ & EPR-III \\
\hline \multirow[t]{4}{*}{$\mathbf{H}_{\beta 1}$} & $A_{1}$ & 17.81 & 16.96 & 18.95 & 19.45 & $\mathbf{H}_{\alpha}$ & -27.48 & -21.69 & -27.39 & -24.96 \\
\hline & $A_{2}$ & 18.10 & 17.44 & 19.32 & 19.94 & & -18.84 & -12.02 & -18.81 & -14.92 \\
\hline & $A_{3}$ & 21.84 & 20.83 & 22.72 & 23.22 & & -7.17 & -2.47 & -7.68 & -5.75 \\
\hline & $a_{\text {iso }}$ & 19.25 & 18.41 & 20.33 & 20.87 & & -17.83 & -12.06 & -17.96 & -15.21 \\
\hline \multirow[t]{4}{*}{$\mathbf{H}_{\beta 2}$} & $A_{1}$ & 0.01 & -0.24 & 0.35 & 0.1 & $\mathrm{H}_{\beta 1}$ & -9.55 & 27.48 & 30.27 & 31.61 \\
\hline & $A_{2}$ & 0.35 & 0.02 & 0.64 & 0.35 & & -9.06 & 28.1 & 30.66 & 32.05 \\
\hline & $A_{3}$ & 3.99 & 3.52 & 4.11 & 3.75 & & -5.36 & 31.51 & 34.14 & 35.46 \\
\hline & $a_{\text {iso }}$ & 1.45 & 1.10 & 1.70 & 1.40 & & -7.99 & 29.03 & 31.69 & 33.04 \\
\hline \multirow[t]{4}{*}{$\mathbf{H}_{\beta 3}$} & $A_{1}$ & 27.34 & 26.32 & 28.94 & 30.04 & $\mathrm{H}_{\beta 2}$ & 13.3 & 12.65 & 14.47 & 14.97 \\
\hline & $A_{2}$ & 27.63 & 26.72 & 29.19 & 30.34 & & 13.66 & 13.18 & 14.85 & 15.5 \\
\hline & $A_{3}$ & 31.37 & 30.21 & 32.68 & 33.76 & & 17.26 & 16.47 & 18.2 & 18.67 \\
\hline & $a_{\text {iso }}$ & 28.78 & 27.75 & 30.27 & 31.38 & & 14.74 & 14.10 & 15.84 & 16.38 \\
\hline \multirow[t]{4}{*}{$\mathbf{H}_{\beta 4}$} & $A_{1}$ & 22.21 & 21.29 & 23.66 & 24.46 & $\mathbf{H}_{\gamma \mathbf{1}}$ & -1.19 & -1.06 & -1.14 & -1.07 \\
\hline & $A_{2}$ & 22.53 & 21.78 & 23.99 & 24.91 & & -1.1 & -0.99 & -1.07 & -1.01 \\
\hline & $A_{3}$ & 26.21 & 25.18 & 27.41 & 28.21 & & 1.27 & 1.33 & 1.22 & 1.24 \\
\hline & $a_{\text {iso }}$ & 23.65 & 22.75 & 25.02 & 25.86 & & -0.34 & -0.24 & -0.33 & -0.28 \\
\hline \multirow[t]{4}{*}{$\mathbf{H}_{\beta 5}$} & $A_{1}$ & -0.85 & -1.17 & -0.48 & -0.86 & $\mathbf{H}_{\gamma 2}$ & -1.27 & -0.71 & -0.84 & -0.77 \\
\hline & $A_{2}$ & -0.5 & -0.79 & -0.21 & -0.6 & & -1.09 & -0.66 & -0.78 & -0.71 \\
\hline & $A_{3}$ & 3.09 & 2.71 & 3.00 & 2.75 & & 1.28 & 0.71 & 0.57 & 0.61 \\
\hline & $a_{\text {iso }}$ & 0.58 & 0.25 & 0.77 & 0.43 & & -0.36 & -0.22 & -0.35 & -0.29 \\
\hline \multirow[t]{4}{*}{$\mathbf{H}_{\beta 6}$} & $A_{1}$ & 24.19 & 23.29 & 25.64 & 26.4 & $\mathbf{H}_{\gamma 3}$ & -0.84 & -1.17 & -0.47 & -1.26 \\
\hline & $A_{2}$ & 24.43 & 23.55 & 25.88 & 26.76 & & -0.78 & -0.99 & -1.54 & -1.06 \\
\hline & $A_{3}$ & 28.18 & 26.99 & 29.12 & 30.15 & & 0.6 & 1.32 & 0.75 & 1.18 \\
\hline & $a_{\text {iso }}$ & 25.6 & 24.61 & 26.88 & 27.77 & & -034 & -0.28 & -0.42 & -0.38 \\
\hline \multirow[t]{4}{*}{$\mathbf{H}_{1}$} & $A_{1}$ & -6.4 & -4.65 & -6.44 & -5.48 & $\mathrm{H}_{1}$ & -7.09 & -4.17 & -7.14 & -6.15 \\
\hline & $A_{2}$ & -5.77 & -3.84 & -5.73 & -4.5 & & -6.17 & -3.48 & -6.15 & -4.88 \\
\hline & $A_{3}$ & -2.65 & -1.32 & -2.74 & -2.08 & & -2.7 & -3.27 & -2.79 & -2.08 \\
\hline & $a_{\text {iso }}$ & -4.94 & -3.27 & -4.97 & -4.02 & & -5.32 & -3.64 & -5.36 & -4.37 \\
\hline \multirow[t]{4}{*}{$\mathbf{H}_{2}$} & $A_{1}$ & 1.48 & 0.21 & 1.3 & 0.35 & $\mathbf{H}_{2}$ & 1.46 & -0.69 & 1.35 & 0.38 \\
\hline & $A_{2}$ & 1.59 & 0.74 & 1.62 & 1 & & 1.62 & 0.43 & 1.73 & 1.1 \\
\hline & $A_{3}$ & 3.26 & 1.88 & 2.96 & 1.95 & & 3.34 & 3.32 & 3.1 & 2.06 \\
\hline & $a_{\text {iso }}$ & 2.11 & 0.94 & 1.96 & 1.10 & & 2.14 & 1.02 & 2.06 & 1.18 \\
\hline \multirow[t]{4}{*}{$\mathbf{H}_{3}$} & $A_{1}$ & -8.18 & -6.81 & -8.3 & -7.71 & $\mathrm{H}_{3}$ & -9.08 & -5.03 & -9.21 & -8.56 \\
\hline & $A_{2}$ & -5.46 & -3.75 & -5.56 & -4.55 & & -6.06 & -4.46 & -6.17 & -5.06 \\
\hline & $A_{3}$ & -2.02 & -0.9 & -2.25 & -1.81 & & -2.26 & -3.26 & -2.5 & -2.01 \\
\hline & $a_{\text {iso }}$ & -5.22 & -3.82 & -5.37 & -4.69 & & -5.80 & -4.25 & -5.96 & -5.21 \\
\hline \multirow[t]{4}{*}{$\mathbf{H}_{4}$} & $A_{1}$ & 1.47 & 0.21 & 1.31 & 1.85 & $\mathbf{H}_{4}$ & 1.44 & -2.29 & 1.34 & 0.37 \\
\hline & $A_{2}$ & 1.59 & 0.74 & 1.63 & 1.2 & & 1.6 & 1.1 & 1.7 & 1.09 \\
\hline & $A_{3}$ & 3.27 & 1.89 & 2.97 & 0.25 & & 3.32 & 4.25 & 3.08 & 2.08 \\
\hline & $a_{\text {iso }}$ & 2.11 & 0.95 & 1.97 & 1.10 & & 2.12 & 1.02 & 2.04 & 1.18 \\
\hline \multirow[t]{4}{*}{$\mathbf{H}_{5}$} & $A_{1}$ & -6.4 & -4.65 & -6.43 & -5.45 & $\mathbf{H}_{5}$ & -6.76 & -4.38 & -6.66 & -5.66 \\
\hline & $A_{2}$ & -5.68 & -3.77 & -5.64 & -4.42 & & -6.17 & -3.8 & -6.01 & -4.85 \\
\hline & $A_{3}$ & -2.62 & -1.3 & -2.72 & -2.04 & & -2.7 & -2.59 & -2.57 & -1.88 \\
\hline & $a_{\text {iso }}$ & -4.90 & -3.24 & -4.93 & -3.97 & & -5.21 & -3.59 & -5.08 & -4.13 \\
\hline
\end{tabular}




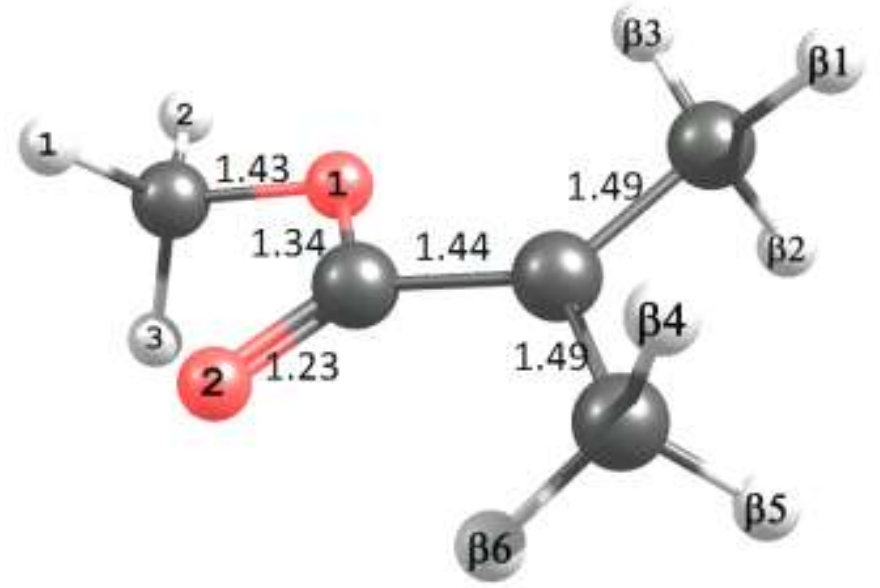

TABLE 4S. Calculated anisotropic hyperfine splitting constants $(\mathrm{G})$ of the $\mathrm{H}$ atom addition radical of methyl methacrylate.

\begin{tabular}{|c|c|c|c|c|c|}
\hline & & \multicolumn{2}{|l|}{ M05-2X } & \multicolumn{2}{|l|}{ B3LYP } \\
\hline & & 6-31+G* & EPR-III & $6-31+G^{*}$ & EPR-III \\
\hline \multirow[t]{4}{*}{$\mathbf{H}_{\beta 1}$} & $A_{1}$ & 14.02 & 13.73 & 14.96 & 15.9 \\
\hline & $A_{2}$ & 14.21 & 14.09 & 15.2 & 16.25 \\
\hline & $A_{3}$ & 18.51 & 18.17 & 19.28 & 20.2 \\
\hline & $a_{\text {iso }}$ & 15.58 & 15.33 & 16.48 & 17.45 \\
\hline \multirow{4}{*}{$\mathbf{H}_{\beta 2}$} & $A_{1}$ & 34.00 & 33.98 & 36.35 & 38.96 \\
\hline & $A_{2}$ & 34.70 & 34.74 & 37 & 39.54 \\
\hline & $A_{3}$ & 39.00 & 38.86 & 41.07 & 43.63 \\
\hline & $a_{\text {iso }}$ & 35.90 & 35.86 & 38.14 & 40.71 \\
\hline \multirow[t]{4}{*}{$\mathbf{H}_{\beta 3}$} & $A_{1}$ & 2.74 & 2.58 & 3.01 & 3.13 \\
\hline & $A_{2}$ & 2.92 & 2.82 & 3.16 & 3.37 \\
\hline & $A_{3}$ & 7.09 & 6.87 & 7.18 & 7.3 \\
\hline & $a_{\text {iso }}$ & 4.25 & 4.09 & 4.45 & 4.60 \\
\hline \multirow[t]{4}{*}{$\mathbf{H}_{\beta 4}$} & $A_{1}$ & 31.01 & 30.8 & 33.13 & 35.42 \\
\hline & $A_{2}$ & 31.48 & 31.33 & 33.59 & 35.84 \\
\hline & $A_{3}$ & 35.85 & 35.55 & 37.74 & 39.98 \\
\hline & $a_{\text {iso }}$ & 32.78 & 32.56 & 34.82 & 37.08 \\
\hline \multirow{4}{*}{$\mathbf{H}_{\beta 5}$} & $A_{1}$ & 18.74 & 18.44 & 20.06 & 21.35 \\
\hline & $A_{2}$ & 19.09 & 18.94 & 20.46 & 21.85 \\
\hline & $A_{3}$ & 23.34 & 22.98 & 24.46 & 25.77 \\
\hline & $a_{\text {iso }}$ & 20.39 & 20.12 & 21.66 & 22.99 \\
\hline \multirow[t]{4}{*}{$\mathbf{H}_{\beta 6}$} & $A_{1}$ & 0.58 & 0.47 & 0.62 & 0.62 \\
\hline & $A_{2}$ & 0.92 & 0.85 & 1.04 & 1.06 \\
\hline & $A_{3}$ & 4.8 & 4.62 & 4.7 & 4.65 \\
\hline & $a_{\text {iso }}$ & 2.10 & 1.98 & 2.12 & 2.11 \\
\hline
\end{tabular}




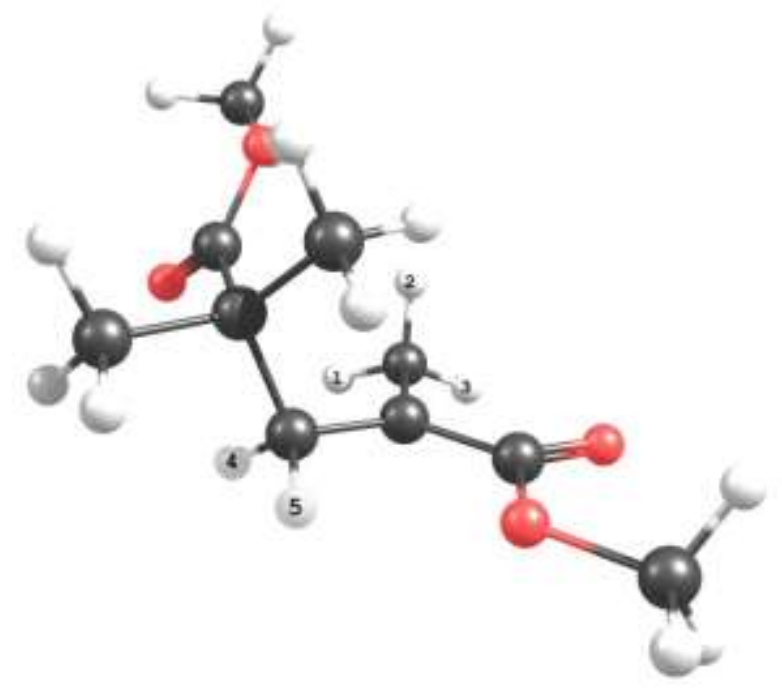

TABLE 5S. Calculated anisotropic hyperfine splitting constants $(\mathrm{G})$ of the PMMA radical.

\begin{tabular}{|l|l|r|r|r|r|}
\hline & & \multicolumn{2}{|c|}{ M05-2X } & & B3LYP \\
\hline & & $\mathbf{6 - 3 1 + G ^ { * }}$ & EPR-III & $\mathbf{6 - 3 1 + G}$ & EPR-II \\
\hline $\mathbf{H}_{\boldsymbol{\beta} \mathbf{1}}$ & $\boldsymbol{A}_{\mathbf{1}}$ & 9.11 & 8.93 & 9.94 & 10.61 \\
& $\boldsymbol{A}_{\mathbf{2}}$ & 9.31 & 9.32 & 10.16 & 11.00 \\
& $\boldsymbol{A}_{\mathbf{3}}$ & 13.44 & 13.2 & 14.11 & 14.75 \\
& $\boldsymbol{a}_{\text {iso }}$ & 10.62 & 10.48 & 11.40 & 12.12 \\
\hline $\mathbf{H}_{\boldsymbol{\beta} \mathbf{2}}$ & $\boldsymbol{A}_{\mathbf{1}}$ & 36.15 & 36.14 & 38.88 & 41.86 \\
& $\boldsymbol{A}_{\mathbf{2}}$ & 36.76 & 36.79 & 39.41 & 42.28 \\
& $\boldsymbol{A}_{\mathbf{3}}$ & 41.00 & 40.89 & 43.44 & 46.36 \\
& $\boldsymbol{a}_{\text {iso }}$ & 37.97 & 37.94 & 40.58 & 43.50 \\
\hline $\mathbf{H}_{\boldsymbol{\beta} 3}$ & $\boldsymbol{A}_{\mathbf{1}}$ & 6.951 & 6.83 & 7.68 & 8.26 \\
& $\boldsymbol{A}_{\mathbf{2}}$ & 7.483 & 7.51 & 8.27 & 8.98 \\
& $\boldsymbol{A}_{\mathbf{3}}$ & 11.426 & 11.25 & 12.01 & 12.55 \\
& $\boldsymbol{a}_{\text {iso }}$ & 8.62 & 8.53 & 9.32 & 9.93 \\
\hline $\mathbf{H}_{\boldsymbol{\beta} \mathbf{4}}$ & $\boldsymbol{A}_{\mathbf{1}}$ & 15.03 & 14.95 & 16.71 & 17.88 \\
& $\boldsymbol{A}_{\mathbf{2}}$ & 15.18 & 15.22 & 16.90 & 18.12 \\
& $\boldsymbol{A}_{\mathbf{3}}$ & 19.58 & 19.45 & 21.11 & 22.26 \\
& $\boldsymbol{a}_{\text {iso }}$ & 16.60 & 16.54 & 18.24 & 19.42 \\
\hline $\mathbf{H}_{\boldsymbol{\beta} 5}$ & $\boldsymbol{A}_{\mathbf{1}}$ & 1.13 & 1.03 & 1.56 & 1.64 \\
& $\boldsymbol{A}_{\mathbf{2}}$ & 1.40 & 1.26 & 1.74 & 1.85 \\
& $\boldsymbol{A}_{\mathbf{3}}$ & 5.69 & 5.48 & 5.91 & 5.94 \\
& $\boldsymbol{a}_{\text {iso }}$ & 2.74 & 2.59 & 3.07 & 3.14 \\
\hline
\end{tabular}




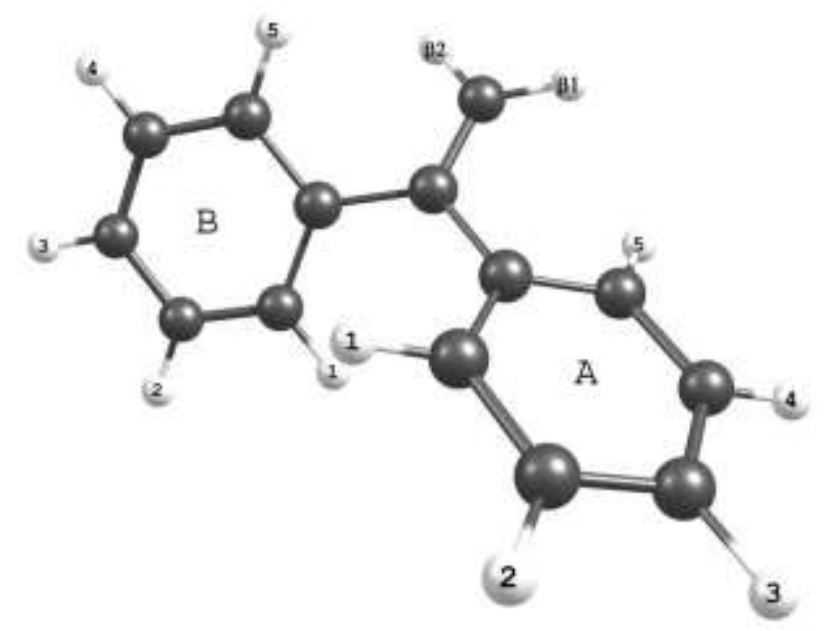

TABLE 6S. Calculated anisotropic hyperfine splitting constants (G) of the 1,1diphenylethylene cation radical.

\begin{tabular}{|c|c|c|c|c|c|}
\hline & & \multicolumn{2}{|c|}{ M05-2X } & \multicolumn{2}{|c|}{ B3LYP } \\
\hline & & $6-31+G *$ & EPR-III & 6-31+G* & EPR-III \\
\hline \multirow{4}{*}{$\mathrm{H}_{\beta 1}$} & $A_{1}$ & -22.37 & -19.16 & -20.05 & -18.38 \\
\hline & $A_{2}$ & -16.27 & -13.14 & -14.20 & -11.81 \\
\hline & $A_{3}$ & -5.96 & -4.46 & -4.75 & -3.41 \\
\hline & $a_{\text {iso }}$ & -14.87 & -12.25 & -13.00 & -11.20 \\
\hline \multirow[t]{4}{*}{$\mathrm{H}_{\beta 2}$} & $A_{1}$ & -22.37 & -19.16 & -20.05 & -18.37 \\
\hline & $A_{2}$ & -16.27 & -13.14 & -14.20 & -11.81 \\
\hline & $A_{3}$ & -5.96 & -4.46 & -4.75 & -3.41 \\
\hline & $a_{\text {iso }}$ & -14.87 & -12.25 & -13.00 & -11.20 \\
\hline \multirow[t]{4}{*}{$\mathrm{H}_{1}$} & $A_{1}$ & $-2.15 /-2.15$ & $-1.77 /-1.77$ & $-1.59 /-1.59$ & $-1.42 /-1.42$ \\
\hline & $A_{2}$ & $-2.03 /-2.03$ & $-1.57 /-1.57$ & $-1.26 /-1.26$ & $-1.06 /-1.06$ \\
\hline & $A_{3}$ & $-0.14 /-0.14$ & $0.21 / 0.21$ & $0.31 / 0.31$ & $0.50 / 0.50$ \\
\hline & $a_{\text {iso }}$ & $-1.44 /-1.44$ & $-1.04 /-1.04$ & $-0.85 /-0.85$ & $-0.66 /-0.66$ \\
\hline \multirow[t]{4}{*}{$\mathrm{H}_{2}$} & $A_{1}$ & $0.60 / 0.60$ & $0.21 / 0.21$ & $0.12 / 1.21$ & $-0.03 /-.0 .3$ \\
\hline & $A_{2}$ & $1.02 / 1.02$ & $0.73 / 0.73$ & $0.63 / 0.63$ & $0.48 / 0.48$ \\
\hline & $A_{3}$ & $1.42 / 1.42$ & $1.00 / 1.00$ & $0.90 / 0.90$ & $0.78 / 0.78$ \\
\hline & $a_{\text {iso }}$ & $1.01 / 1.01$ & $0.65 / 0.65$ & $0.55 / 0.55$ & $0.41 / 0.41$ \\
\hline \multirow[t]{4}{*}{$\mathrm{H}_{3}$} & $A_{1}$ & $-5.32 /-5.32$ & $-4.77 /-4.77$ & $-4.86 /-4.86$ & $-4.62 /-4.62$ \\
\hline & $A_{2}$ & $-3.79 /-3.79$ & $-3.12 /-3.12$ & $-3.43 /-3.43$ & $-2.97 /-2.97$ \\
\hline & $A_{3}$ & $-1.27 /-1.27$ & $-0.85 /-0.86$ & $-0.92 /-0.92$ & $-0.72 /-0.72$ \\
\hline & $a_{\text {iso }}$ & $-3.46 /-3.46$ & $-2.91 /-2.91$ & $-3.07 /-3.07$ & $-2.77 /-2.77$ \\
\hline \multirow[t]{4}{*}{$\mathrm{H}_{4}$} & $A_{1}$ & $0.09 / 0.09$ & $-0.22 / 0.22$ & $-0.35 /-0.35$ & $-0.48 /-0.48$ \\
\hline & $A_{2}$ & $0.59 / 0.59$ & $0.30 / 0.30$ & $0.10 / 0.10$ & $-0.07 /-0.07$ \\
\hline & $A_{3}$ & $0.90 / 0.90$ & $0.59 / 0.59$ & $0.55 / 0.55$ & $0.43 / 0.43$ \\
\hline & $a_{\text {iso }}$ & $0.53 / 0.53$ & $0.22 / 0.22$ & $0.10 / 0.10$ & $-0.04 /-0.04$ \\
\hline \multirow[t]{4}{*}{$\mathrm{H}_{5}$} & $A_{1}$ & $-2.67 /-2.67$ & $-2.36 /-2.36$ & $-2.15 /-2.15$ & $-2.06 /-2.06$ \\
\hline & $A_{2}$ & $-1.12 /-1.12$ & $-0.80 /-0.80$ & $-0.69 /-0.69$ & $-0.60 /-0.60$ \\
\hline & $A_{3}$ & $-0.69 /-0.69$ & $-0.42 /-0.42$ & $-0.19 /-0.19$ & $-0.16 /-1.16$ \\
\hline & $a_{\text {iso }}$ & $-1.49 /-1.49$ & $-1.19 /-1.19$ & $-1.01 /-1.01$ & $-0.94 /-0.94$ \\
\hline
\end{tabular}

